\title{
1 Exploratory polarization facilitates mating partner selection in Saccharomyces cerevisiae
}

2 Manuella R. Clark-Cotton ${ }^{1}$, Nicholas T. Henderson ${ }^{1}$, Michael Pablo ${ }^{2,3}$, Debraj Ghose ${ }^{1}$, Timothy C. Elston ${ }^{4}$, 3 and Daniel J. Lew ${ }^{1 *}$

4

$5 \quad{ }^{1}$ Department of Pharmacology and Cancer Biology, Duke University, Durham, North Carolina

$6 \quad{ }^{2}$ Department of Chemistry, UNC Chapel Hill, Chapel Hill, NC

$7 \quad{ }^{3}$ Program in Molecular and Cellular Biophysics, UNC Chapel Hill, Chapel Hill, NC

$8 \quad{ }^{4}$ Department of Pharmacology and Computational Medicine Program, UNC Chapel Hill, Chapel Hill, NC

Running title: Exploratory polarization facilitates mating

Corresponding author: daniel.lew@duke.edu

Summary: Budding yeast use pheromones to select a single mating partner in crowded environments. This paper shows that cells assemble mobile polarity sites that both sense and secrete pheromone, enabling a search strategy whereby encounters between the polarity sites of partner cells trigger commitment.

Abstract:

Yeast decode pheromone gradients to locate mating partners, providing a model for chemotropism. How yeast polarize toward a single partner in crowded environments is unclear. Initially, cells often polarize in unproductive directions, but then they relocate the polarity site until two partners' polarity sites align, whereupon the cells "commit" to each other by stabilizing polarity to promote fusion. Here we address the role of the early mobile polarity sites. We found that commitment by either partner failed if just one partner was defective in generating, orienting, or stabilizing its mobile polarity sites. Mobile polarity sites were enriched for pheromone receptors and $\mathrm{G}$ proteins, and we suggest that such sites engage in an exploratory search of the local pheromone landscape, stabilizing only when they detect elevated pheromone levels. Mobile polarity sites were also enriched for pheromone secretion factors, and simulations suggest that only focal secretion at polarity sites would produce high pheromone concentrations at the partner's polarity site, triggering commitment. 


\section{INTRODUCTION}

Directed growth (chemotropism) or movement (chemotaxis) in response to a chemical signal is critical for biological processes including aggregation in Dictyostelium discoideum (Nichols et al., 2015), pollen tube growth during plant fertilization (Higashiyama and Takeuchi, 2015), axon guidance during neural development (Bellon and Mann, 2018), and neutrophil migration in the mammalian immune response (Sarris and Sixt, 2015). However, the mechanisms by which cells choose the direction of polarized growth or movement are incompletely understood.

Saccharomyces cerevisiae exhibits polarized growth during mating, culminating in the fusion of two cells to form a zygote (Merlini et al., 2013). Because yeast are immotile, two cells must grow toward each other to facilitate membrane fusion. Cells of each mating type, a and $\alpha$, secrete pheromones that are sensed by cognate $\mathrm{G}$ protein-coupled receptors on cells of the opposite mating type. Pheromone sensing triggers the activation of a MAPK cascade, cell cycle arrest in G1, increased transcription of mating-specific genes, and polarized growth toward the mating partner (Dohlman and Thorner, 2001).

Polarized growth is directed by the Rho-GTPase Cdc42, its regulators, and its effectors, which become concentrated at a small region of the cell's cortex (Park and $\mathrm{Bi}, 2007$ ) to form a "polarity site." Polarity sites are assembled by a positive feedback mechanism in which active Cdc42-GTP binds the scaffold protein Bem1, promoting the activation of nearby inactive Cdc42-GDP to form an initial small cluster of polarity factors (Johnson et al., 2011; Kozubowski et al., 2008). Formins (effectors of Cdc42) trigger the orientation of actin cables toward the site, promoting vesicle-mediated delivery of cell wall-remodeling enzymes that enable polarized growth (Pruyne et al., 2004).

Yeast cells prefer partners that make more pheromone (Jackson and Hartwell, 1990a; Jackson and Hartwell, 1990b), and cells exposed to an exogenous gradient of pheromone tend to grow up-gradient (Segall, 1993). Consequently, models of partner selection often depict a cell polarizing growth up a gradient of pheromone that emanates from a single source (Arkowitz, 1999; Ismael and Stone, 2017) (Fig. 1A). However, a stable unidirectional pheromone gradient may be infrequent during mating in the wild. Meiosis of a diploid cell produces four haploid spores (two a, two $\alpha$ ) encased in an ascus. Upon exposure to nutrients, germinating spores from a single ascus can mate with each other, but since each spore is adjacent to two potential partners (Taxis et al., 2005), it is unclear how the resulting pheromone landscape yields orientation toward one partner (Jin et al., 2011; Rappaport and Barkai, 2012) (Fig. 1B). Moreover, germinating spores derived from wild yeast strains often proliferate to form microcolonies (McClure et al., 2018) and switch mating type (Haber, 2012) before mating, so that each cell is likely to have more than one potential partner (Fig. 1C). Even when surrounded by many potential partners, cells choose only one (Jackson and Hartwell, 1990a; Jackson and Hartwell, 1990b). With multiple local pheromone sources that change as cells bud or mate, how do cells reliably orient polarity toward one partner?

For successful mating, the pheromone landscape must be decoded to orient polarity toward the partner. However, imaging of polarity factors revealed that initial polarity sites were not always oriented toward the eventual mating partner in mating mixes (Henderson et al., 2019; Wang et al., 2019) or up the gradient in cells exposed to artificial pheromone gradients (Dyer et al., 2013; Hegemann et al., 2015; Jin et al., 2011; Kelley et al., 2015; Vasen et al., 2020). Rather, the location of the polarity site changed over time, stabilizing at better-oriented locations. In mating mixes, weak clusters of polarity factors appeared, disappeared, and changed position in a chaotic manner (Henderson et al., 2019). After this "indecisive phase" of 10-120 min, cells developed strong, stable polarity sites oriented toward the partner, suggesting that they made a "commitment" to the partner. Similarly, cells exposed to a steep pheromone gradient in a microfluidics device spent a variable interval with weak and mobile polarity 76 sites before developing a strong polarity site at a stable position (Hegemann et al., 2015). These studies 
suggested that yeast cells process spatial information about the local pheromone landscape during a search period of variable duration, then commit to a specific orientation for polarized growth.

Spatial information about the pheromone landscape could be extracted by "global" or "local" sensing strategies (Hegemann and Peter, 2017; Kelley et al., 2015; Martin, 2019). In global sensing, cells compare the concentration of ligand-bound receptors around the cell surface to infer the direction of the pheromone source. In local sensing, cells primarily detect pheromone in a sensitized zone centered around the polarity site, moving the site around to infer the direction of the pheromone source. These models are not mutually exclusive.

Evidence for global sensing comes from the observation that in mating mixes, initial weak polarity sites were oriented toward their eventual mating partners more often than would be expected by chance (Henderson et al., 2019). Thus, some spatial information was available before any polarity sites were visible. Other studies reported that initial polarity sites were frequently oriented toward bud siteselection cues rather than pheromone sources (Vasen et al., 2020; Wang et al., 2019). Regardless of initial orientation, global sensing during the indecisive phase (when polarity sites are weak and mobile) could promote the selection of optimal locations for stable "committed" polarity sites.

Evidence for local sensing comes from the observation that when a strong polarity site is present, pheromone receptors and associated $\mathrm{G}$ proteins accumulate around the polarity site (Ayscough and Drubin, 1998; McClure et al., 2015; Suchkov et al., 2010). Thus, cells with a strong polarity site sense pheromone preferentially in the vicinity of the site. It is unclear whether the weak and transient polarity sites characteristic of the indecisive phase would similarly enable local sensing.

The observations discussed above suggested a potential strategy for partner search that we call "exploratory polarization" (Henderson et al., 2019). One component of this hypothesis is local sensing: this proposes that cells sense pheromone primarily near the indecisive polarity sites. The second component is local pheromone secretion: this proposes that most pheromone is secreted from the indecisive polarity sites, so the pheromone landscape changes as the polarity sites move. When polarity sites in potential partners are not properly aligned, the pheromone released from one cell is dissipated by diffusion and detected at a low concentration at the partner's polarity site (Fig. 1D). However, when two polarity sites face each other (and only in that case), a high concentration of pheromone is detected at each site (Fig. 1D). This stabilizes both sites, leading to spatially and temporally coordinated commitment by both partners. According to this hypothesis, successful communication between two cells requires the simultaneous coorientation of their polarity sites.

\section{8}

A similar strategy was proposed for Schizosaccharomyces pombe, where weak polarity sites formed and disappeared at different locations before commitment (Bendezu and Martin, 2013). Pheromone secretion and sensing factors were enriched at these transient sites, and computational models confirmed that local secretion and sensing/signaling would promote effective partner location in realistic geometries and timescales (Merlini et al., 2016). Thus, an exploratory polarization strategy might be conserved between evolutionarily distant fungi (Martin, 2019).

In this study, we tested the ability of wildtype cells to locate partners that are impaired in either the formation, localization, or stabilization of weak, indecisive phase polarity sites. Wildtype cells appeared to search for an extended indecisive period but did not commit (polarize stably) to the aberrant partners. We also confirmed that transient polarity sites are enriched in pheromone sensing, signaling, and secretion proteins. Simulations of the pheromone landscape based on documented pheromone secretion rates provide quantitative support for the idea that pheromone levels sufficient to promote commitment are only achieved when polarity sites of mating partners become aligned. We conclude that local sensing and secretion by two cooriented polarity sites enables commitment by a mating pair. 


\section{$\underline{\text { RESULTS }}$}

\section{Behavior of mating cells before commitment to a partner}

Reports of polarity before commitment vary, so we began by re-examining this behavior. Imaging of polarity probes like Bem1 (Fig. $\mathbf{2 A}$ ) in wildtype cells showed weak initial polarity sites that exhibited chaotic "indecisive" behavior before becoming strong, stable polarity sites facing the partner (Henderson et al., 2019). However, imaging of probes for sensing/signaling proteins (Fig. 2A) suggested that cells undergo a more stereotyped behavior, with initial polarization always adjacent to the previous site of cytokinesis, followed by steady unidirectional tracking toward the eventual mating partner (Wang et al., 2019). We considered the possibility that probe selection might affect conclusions about cells' behavior prior to commitment.

The Bem1 probe concentrates at the mother-bud neck during cytokinesis. To control for possible bias against neck-proximal initial polarization, we visualized the Cdc42 effector Ste20, which does not concentrate at the neck during cytokinesis. Scoring of initial Ste20 polarization did not reveal a significant bias to any sector (Fig. $2 B-D)(p=0.40, n=86)$. Analyzing cells that were or were not directly adjacent to a potential partner ("isolated" vs. "adjacent", Fig. $2 C, D$ ) revealed that isolated cells showed a non-random distribution ( $p=0.05, n=49)$, while adjacent cells did not $(p=0.14, n=37)$. Thus, under our mating conditions, isolated cells might have a mild preference for the default site, but those that are near a mating partner do not. contrast to the directional tracking described for the $\alpha$-factor receptor Ste2 (Wang et al., 2019). To compare the behavior of Ste2 and polarity probes, we imaged mating in cells harboring both STE2-sfGFP and either BEM1-tdTomato or SPA2-mCherry, a formin regulator that colocalizes with indecisive polarity sites (Henderson et al., 2019). Cortical Ste2 behavior varied, but most cells developed Ste 2 crescents that gradually became broader and more intense (Fig. 2E). Neither Ste2 nor polarity factors displayed obvious directional tracking, as shown in three examples chosen to illustrate the range of behaviors (Fig. 2E). In one cell, the polarity factors exhibited unidirectional movement from the initial polarity site to the final site (top), in a second, initial polarization occurred near the partner with minimal movement (middle), and in a third, polarity factors showed erratic movement over the cortex (bottom). Taken together, these observations suggest that polarity factors initially concentrate at a small site on the cortex, then exhibit indecisive rather than stereotyped behavior before commitment.

\section{Pheromone sensing and secretion are enriched at transient polarity sites}

Pheromone receptors and $\mathrm{G}$ proteins are concentrated near stable polarity sites (Ayscough and Drubin, 1998; McClure et al., 2015; Suchkov et al., 2010), but it was unclear whether the transient polarity sites characteristic of the indecisive period would similarly concentrate these factors. We imaged strains harboring both BEM1-tdTomato and either STE2-SfGFP (receptor) or GFP-STE4 (Gß) in mating mixes, identified time points at which a Bem1-tdTomato site was present, and assessed by visual comparison whether the Ste2 or Ste4 signal was colocalized. Both the receptor and G $\beta$ were sometimes colocalized with polarity factors (Fig. $3 A$ ). The frequency of detectable colocalization during the indecisive period varied between cells (Fig. $\mathbf{3 B}$ ), but these data suggest that even transient polarity sites can create detectable enrichment of pheromone sensing proteins (Fig. 3 C). pheromones are secreted by different mechanisms: $\alpha$-factor is delivered to the plasma membrane in secretory vesicles, and a-factor is secreted by a transporter, Ste6 (Michaelis and Barrowman, 2012). As with the pheromone sensing probes, GFP-Sec4 (a marker of secretory vesicles) and Ste6-sfGFP were 
It is unclear whether the degree of enrichment we observed would enable exploratory polarization. If much of the pheromone sensing and secretion is distributed around the cortex, then cells could also decode pheromone gradients using a global strategy, integrating the spatial distribution of pheromone over time and polarizing in the direction that provides the strongest signal. This model does not ascribe any role to the weak and transient polarity sites that are seen prior to commitment.

\section{Wildtype cells fail to commit to partners that lack polarity sites}

To investigate the role of indecisive polarity sites, we asked how wildtype cells respond to partners that cannot polarize Cdc42. Because loss of Cdc42-GTP abrogates pheromone-responsive signaling (Simon et al., 1995; Zhao et al., 1995), we began by activating Cdc42 all over the cortex. To activate Cdc42, we overexpressed a membrane-targeted, constitutively-active guanine nucleotide exchange factor (GEF: $M T-G F P-C D C 24^{38 A}$ ), a strategy previously shown to abrogate polarization (Kuo et al., 2014). To ensure that the mutants (mating type a) were arrested in $\mathrm{G} 1$, we added $10 \mu \mathrm{M} \alpha$-factor. In arrested mutant cells, both Bem1-tdTomato and MT-GFP-Cdc24 $4^{38 \mathrm{~A}}$ were broadly distributed on the plasma membrane (Fig. S1).

In mating mixes with wildtype a cells, wildtype $\alpha$ cells (Bem1-tdTomato) formed polarity sites that varied in intensity, location, and number, typical of the indecisive period, before committing to a partner and fusing (Fig. 4A, Movie 2). However, when mixed with MT-CDC24 $4^{38 A}$ mutants, wildtype $\alpha$ cells did not commit to the mutant partners, instead displaying extended indecisive behavior (Fig. 4B, Movie 3). Under these conditions, wildtype pairs mated at a high frequency during 2-h movies (mating efficiency $\mathrm{ME}=0.62, \mathrm{n}=162$ ). However, no wildtype cells were observed to mate with the unpolarized mutants ( $M E=0, n=151, p<0.01)$, even when imaged for $3 \mathrm{~h}$.

The failure of MT-GFP-CDC24 ${ }^{38 A}$ mutants to communicate effectively might stem from excess Cdc42GTP, rather than the lack of Cdc42 polarization. To address that possibility, we performed a similar experiment with strains lacking Cdc42-directed GEF activity. At the restrictive temperature, $c d c 24-4^{t s}$ mutants fail to polarize and have predominantly inactive Cdc42-GDP (Adams et al., 1990; Atkins et al., 2013). However, $c d c 24-4^{t s}$ mutants also fail to activate Ste20 and cannot respond to pheromone. We restored pheromone signaling by introducing the constitutively-active ste20 ${ }^{\triangle C R I B}$, which eliminates the need for Cdc42-GTP to respond to pheromone (Moskow et al., 2000). Again, we added $10 \mu \mathrm{M} \alpha$-factor to ensure $\mathrm{G} 1$ arrest. At 35 or $37^{\circ} \mathrm{C}$, wildtype cells (Bem1-GFP) displayed both indecisive and committed behavior in pairings with other wildtype cells (Fig. 4C, Movie 4), but when mixed with mutants, they again exhibited prolonged indecisive behavior (Fig. 4D, Movie 5). At $35^{\circ} \mathrm{C}$, wildtype cells mated at high frequency with wildtype partners $(\mathrm{ME}=0.80, \mathrm{n}=115)$, but did not mate with unpolarized mutants $(\mathrm{ME}=$ $0, \mathrm{n}=83, \mathrm{p}<0.01$ ).

To quantify the behavior of the wildtype partners in these mixes, we developed an unbiased scoring method to distinguish indecisive and committed behavior based on the Bem1 probe. We calculated the correlation between the spatial distribution of pixel intensities in a cell between consecutive time points. If the polarity sites are mobile, the correlation is low, but if the cells commit, the correlation is high (Fig. 5A). In wildtype mating mixes, this "spatial autocorrelation" generally increased at commitment. 50 mating pairs were scored to select a commitment threshold that minimized false positives and false negatives (Fig. $\mathbf{S 2 A}$ ). Because polarity sites were brighter and less variable at $30^{\circ} \mathrm{C}$ than $35^{\circ} \mathrm{C}$, we chose a different threshold for each condition (Fig. S2B).

Whereas $48 / 50$ cells mixed with wildtype partners developed spatial autocorrelation above threshold at $30^{\circ} \mathrm{C}, 0 / 20$ cells mixed with $M T-C D C 24^{38 A}$ partners did so, despite prolonged imaging (Fig. S3). Similarly, $42 / 50$ cells mixed with wildtype partners crossed the threshold at $35^{\circ} \mathrm{C}$, but only $5 / 20$ cells mixed with cdc24-4ts partners did so (Fig. S4). We conclude that wildtype cells do not commit to MT-CDC24 ${ }^{38 A}$ or 
$c d c 24-4^{t s}$ mutants as they do to wildtype partners ( $p<0.01$ for both). Examples of spatial autocorrelation traces are shown in Fig. 5 B.

Because unpolarized mutants might secrete less pheromone than wildtype cells, we assessed the capacity of the mutants to induce cell cycle arrest in wildtype partners in mating mixes, calculating the percentage of cells that budded during attempted mating. Similar percentages of wildtype cells budded when attempting to mate with either wildtype cells or unpolarized mutants ( $M T-C D C 24^{38 A}, \mathrm{p}=0.29$; $\left.c d c 24-4^{t s}, p=0.17\right)$, demonstrating that the mutants secrete sufficient pheromone to trigger and maintain cell cycle arrest (Fig. $\mathbf{5 C}$ ). We conclude that indecisive polarity sites are critical to communicate a cell's location to its partner, and that without such communication, a wildtype cell does not commit.

\section{Wildtype cells fail to commit to constitutively indecisive partners}

The exploratory polarization hypothesis posits that cells commit when they sense concentrated pheromone released from an immediately apposed partner polarity site. If consistently high local signaling is required to sustain commitment, then a wildtype cell would be unable to commit to a partner that was unable to stabilize the position of its own polarity site, even if that partner had mobile polarity sites.

Polarity sites can be stabilized by either of two parallel pathways, each of which recruits Cdc 24 to the cortex (Dyer et al., 2013). One pathway depends on binding of the scaffold Far1 to Cdc24, which is impaired in the cdc24-m1 mutant (Butty et al., 1998; Nern and Arkowitz, 1998; Nern and Arkowitz, 1999; Valtz et al., 1995). The other depends on the Ras-family GTPase Rsr1 (Bender and Pringle, 1989; Chant and Herskowitz, 1991). When treated with concentrated pheromone, mutants lacking both of these pathways (cdc24-m1 rsr1 1 ) exhibit constitutively mobile polarity sites (Dyer et al., 2013; Nern and Arkowitz, 2000), and we expected that they would similarly exhibit constitutively mobile sites in a mating mix.

When mixed with wildtype $\alpha$ cells, $c d c 24-m 1 r s r 1 \Delta$ a cells formed constitutively mobile polarity sites, reminiscent of indecisive period behavior (Fig. 6A, Movie 6). Notably, their wildtype partners (Bem1tdTomato) exhibited similar behavior, arresting in $\mathrm{G} 1$ and forming transient polarity sites but failing to commit. We asked if this phenotype was mating type-specific by repeating this experiment with wildtype a cells, and found that these also failed to commit to $\alpha$ partners with constitutively mobile polarity sites (Fig. 6B,C). Consistent with earlier work (Nern and Arkowitz, 1999), mating mixes between wildtype and cdc24- $m 1 \mathrm{rsr} 1 \Delta$ strains showed poor mating efficiency (ME $=0.01, \mathrm{n}=189, \mathrm{p}<0.01$ ). As with the unpolarized mutants, $0 / 20$ wildtype cells randomly selected for spatial autocorrelation analysis committed to $c d c 24-m 1$ rsr1 $\Delta$ partners (Fig. 6D). Furthermore, no budding events were observed among wildtype cells that were adjacent to potential mating partners $(n=75)$, confirming that the pheromone signal released by $c d c 24-m 1 r s r 1 \Delta$ strains was sufficent to sustain arrest in wildtype potential partners (Fig. 5C). We conclude that effective communication with a partner requires that the partner possess indecisive polarity sites and is capable of stabilizing them.

\section{Wildtype cells can commit to partners that are stably oriented toward them}

Previous studies indicated that mating can still occur, albeit at reduced frequency, in conditions where the a-type mating partner is "confused" - that is, unable to locate partner cells-due to the addition of saturating levels of $\alpha$-factor to the medium (Dorer et al., 1997; Dorer et al., 1995). Saturating $\alpha$-factor causes cell cycle arrest and stable polarization, but it is unclear how such cells mate. We speculated that the low frequency of successful mating in these conditions might reflect fortuitous instances in which the "confused" cell happens to orient directly toward an a partner, and that during its own indecisive phase, the $\alpha$ cell finds and commits to the confused cell. Alternatively, the presence of saturating $\alpha$ factor may allow a "unilateral" mating in which only one partner needs to orient properly. 
We imaged wildtype cells in a mating mix with $10 \mu \mathrm{M} \alpha$-factor. a cells polarized stably and grew in a single direction which usually did not point to an $\alpha$ partner. The $\alpha$ cells next to such "misoriented" a cells exhibited prolonged indecisive behavior and did not commit or mate (Fig. 7, Movie 7). In the rarer instances in which an a cell polarized toward an $\alpha$ partner, some $\alpha$ cells polarized toward the a cell's polarity site and mated (Fig. 8A, Movie 8). Thus, cells can mate with partners that stably orient in the correct direction, even if that orientation develops by chance and not through a search process. This accounts for all of the mating events we observed $(n=14)$. Curiously, cells were able to mate even if the polarity site of the non-confused partner was less stable than in typical pairings, as reflected in the fact that the spatial autocorrelation metric did not reach the commitment threshold (Fig. $8 C$ ). Cells that did not mate (regardless of orientation) never reached the commitment threshold (Fig. $7 \mathbf{B}, \mathbf{8 C}$ ). We did not observe any fusion events without preceding coorientation, suggesting that only if the two partners' polarity sites are oriented toward each other do the cells commit and mate. Interestingly, we also observed instances where pairs that appeared to be properly oriented failed to mate under "confusion" conditions ( $n=36)$ (Fig. 8B, Movie 9). The basis for this behavior remains unknown.

\section{Simulating the pheromone landscape experienced by mating cells}

Our findings indicate that for yeast cells to commit to a mating partner, pheromone secretion must be oriented from each partner toward the other. Unpolarized or misdirected secretion did not trigger commitment. To understand this, we first estimated the pheromone concentration that might be detected by a partner next to a cell secreting pheromone. An $\alpha$ cell arrested in G1 following exposure to a-factor secretes approximately 1400 molecules of $\alpha$-factor per second (Rogers et al., 2012). Assuming that the pheromone profile reaches steady state, a cell that secretes pheromone in an unpolarized manner would generate a local pheromone concentration of only $0.5 \mathrm{nM}$ (Materials and Methods). However, if the same amount of pheromone were secreted in a focused manner from a small zone, then the local concentration could exceed $5 \mathrm{nM}$, comparable to the receptor $\mathrm{K}_{\mathrm{D}}$ (Jenness and Spatrick, 1986). As stable polarization requires a higher pheromone concentration than cell cycle arrest (Hegemann et al., 2015; McClure et al., 2015; Moore, 1983; Paliwal et al., 2007), this calculation suggests that cells adjacent to unpolarized partners may fail to commit simply because they do not sense a sufficiently high concentration of pheromone.

To better understand how a "local sensing" cell that detects pheromone at a zone surrounding the polarity site would respond to an adjacent partner cell, we simulated an arrangement with two spheres: a pheromone emitter and a pheromone receiver. The spheres were $250 \mathrm{~nm}$ apart (the minimal possible distance based on the combined thickness of two cell walls) to simulate cells that are touching (Fig. 9A). $\alpha$-factor is secreted by exocytosis of vesicles, which fuse at a rate of $\sim 0.83 / s$ (Dyer et al., 2013). Thus, with an overall $\alpha$-factor release rate of 1400/s (Rogers et al., 2012), the average number of pheromone molecules in a vesicle would be $\sim 1680$.

We simulated pheromone release in one of two patterns: global secretion, where each vesicle releases its pheromone at a random position on the surface of the emitter, or local secretion, where each vesicle releases pheromone at the pole that abuts the receiver (Fig. 9B). Following secretion, pheromone molecules were assumed to diffuse freely unless reflected from the surfaces of the two spheres. To simulate pheromone sensing in the vicinity of the polarity site, we designated a $\sim 1.3 \mu \mathrm{m}$ diameter patch at several locations $\left(0^{\circ}\right.$ to $180^{\circ}$, changing colors, Fig. 9A) on the receiver, and counted the number of molecules within $0.25 \mu \mathrm{m}$ of the patch surface. Pheromone concentrations calculated in this manner fluctuated dramatically as vesicles were released (Fig. 9C).

Pheromone-receptor unbinding is slow ( $k_{\text {off }}=0.01-0.001 / \mathrm{s}$ ) (Bajaj et al., 2004; Jenness et al., 1983; Raths et al., 1988; Yi et al., 2003), suggesting that receptors would average the local pheromone concentration 
rather than responding rapidly to a transient spike. Temporal averaging of pheromone concentrations in different patches on the receiver indicated that the concentration sensed in the patch facing the emitter was 8-fold higher for simulations with polarized secretion compared to those with global secretion, consistent with the estimates discussed above (Fig. 9D). Thus, if a threshold concentration must be detected to promote commitment, then cells that secrete pheromone in a polarized manner would be much more likely to cross that threshold. Furthermore, the pheromone concentrations sensed at different locations declined much more steeply with distance from the emitter in the simulations with polarized secretion (Fig. 9D). Thus, when secretion and sensing both occur at polarity sites, the concentration sensed by a cell would depend on the relative positions of the two cells' polarity sites, as posited by the exploratory sensing hypothesis.

Unlike $\alpha$-factor, a-factor is exported by the transporter Ste6 (Michaelis and Barrowman, 2012), so that afactor release may occur one molecule at a time (Michaelis and Barrowman, 2012), rather than in vesicular packets. We repeated the simulations discussed above, assuming the same overall production rate but releasing one molecule of pheromone at a time. While the variability in pheromone concentration was greatly reduced (Fig. 9F), the average pheromone concentrations sensed at different locations remained the same (Fig. 9E).

\section{DISCUSSION}

\section{Exploratory polarization underlies partner selection in yeast mating}

Our findings indicate that the transient polarity sites formed during the indecisive period are critical for subsequent commitment to a mating partner. Proteins involved in pheromone sensing, secretion, and signaling were all enriched at these sites, suggesting that they are preferred sites for both pheromone secretion and sensing. Wildtype cells in mating mixes did not commit to partners that lacked polarity sites, partners with constitutively mobile polarity sites, or partners with stable but misoriented polarity sites. These results are fully consistent with the exploratory polarization hypothesis (Fig. 1D), in which transient polarity sites mediate communication between mating partners.

Previous findings indicated that the appearance of a strong, stable polarity site, which we call "commitment," results from detection of a high concentration of pheromone (Hegemann et al., 2015; Henderson et al., 2019; McClure et al., 2015; Moore, 1983). Our findings suggest that pheromone levels sufficient to trigger commitment are only achieved when a partner's polarity site is directly apposed to that in the receiving cell. Simulations based on reported pheromone production rates confirm that local pheromone secretion would expose a well-oriented polarity site to much higher pheromone levels ( 4 $\mathrm{nM})$ than those attainable by a cell secreting pheromone uniformly around its surface $(0.5 \mathrm{nM})$. We conclude that yeast cells normally commit to a partner in response the concentrated pheromone signal that accompanies coorientation of the two cells' polarity sites.

An open question concerns the mechanism whereby the two partner cells' polarity sites "find each other" to become cooriented. One could imagine that polarity sites form, move, and disappear stochastically until coorientation promotes stable commitment, as proposed for "speed dating" in $S$. pombe (Bendezu and Martin, 2013; Merlini et al., 2016). Alternatively, polarity sites may be guided toward each other by pheromone gradients. Our simulations indicate that when pheromone is secreted locally, the mating partner would experience a very steep gradient in pheromone concentration, potentially guiding the movement or formation of polarity sites.

A recent study suggested that initial polarity sites move gradually and directionally toward the partner cell in S. cerevisiae (Wang et al., 2019). In our mating conditions, the movement was more chaotic, without obvious unidirectional tracking in most cells. Nevertheless, it remains possible that the movement is influenced by the pheromone landscape in a manner that accelerates coorientation. Such 
movement could occur via local sensing of pheromone gradients near the polarity site or global sensing of pheromone all over the surface.

\section{Re-evaluating the pheromone landscape of mating cells}

The observation that yeast cells are able to orient polarization toward artificial pheromone sources generated by micropipets (Nern and Arkowitz, 1998; Segall, 1993; Valtz et al., 1995) or microfluidic devices (Brett et al., 2012; Dyer et al., 2013; Hao et al., 2008; Hegemann et al., 2015; Jin et al., 2011; Kelley et al., 2015; Lee et al., 2012; Moore et al., 2008; Moore et al., 2013; Paliwal et al., 2007; Vasen et al., 2020) has focused attention on the mechanism whereby cells decode a stable gradient of pheromone. Although yeast cells are clearly capable of polarizing growth toward an exogenous pheromone source, wildtype cells failed to polarize growth toward partners that were secreting pheromone uniformly around their surface. As such cells would be expected to set up a stable pheromone gradient similar to that from a micropipet, why did their partners not commit?

Experiments that analyze polarization in artificial pheromone gradients generally focus on cells that remain arrested in $\mathrm{G} 1$ for prolonged periods (4-10 h). Cells that are further from the pheromone source arrest only transiently and then resume budding, and these cells are omitted from the analysis of directional polarization in the gradient. However, we suggest that this transiently arrested population may be the most relevant to the behavior of mating cells. In our wildtype by wildtype matings, we found that $12-19 \%$ of cells went on to bud during a 2 -h observation window (Fig. $\mathbf{5 C}$ ). Note that this analysis excludes cells that were not directly adjacent to (touching) potential G1-phase mating partners. Thus, cells that do not mate are unlikely to remain arrested in $\mathrm{G} 1$ for many hours under these circumstances. The simplest explanation for mating failures with unpolarized partners is that yeast cells simply do not secrete enough pheromone to recreate the kinds of gradients produced by microfluidics devices.

Unlike experimental settings with unidirectional gradients, yeast cells in physiological mating scenarios must often discriminate between two or more similarly-distant pheromone sources (McClure et al., 2018; Taxis et al., 2005). Under those circumstances, stable pheromone gradients would seem unlikely, and the findings presented in this and other recent studies (Bendezu and Martin, 2013; Dyer et al., 2013; Henderson et al., 2019; Merlini et al., 2016; Wang et al., 2019) suggest that mating cells operate in the context of a fluctuating pheromone landscape quite unlike the stable gradients studied thus far. Fluctuations occur on several timescales. First, vesicular release of $\alpha$-factor would generate dramatic spikes in pheromone concentration, because each vesicle contains very concentrated ( $4 \mathrm{mM}) \alpha$-factor. However, with an estimated $\alpha$-factor diffusion constant of $150 \mu \mathrm{m}^{2} / \mathrm{s}$, each spike would dissipate to low nM levels very rapidly $(<0.1 \mathrm{~s}, \mathbf{F i g}$. S5A), well before the next spike, generating large second-to-second fluctuations. Second, the movement of the polarity sites during the indecisive phase means that the source of pheromone would relocate on a minute timescale, shifting the local gradients. Third, on a several-minute timescale, the mating or budding of nearby cells would remove them as pheromone sources in the local environment. Thus, physiological pheromone gradients are likely to be transitory, at least until the partners commit to each other. We suggest that the exploratory polarization strategy provides a framework for understanding how yeast cells are able to locate partners and mate successfully in such a dynamic pheromone landscape.

\section{Advantages of exploratory polarization}

The exploratory polarization strategy supported by our findings, like the related speed dating strategy proposed for S. pombe (Bendezu and Martin, 2013; Martin, 2019; Merlini et al., 2016), provides an elegant solution to the problem of choosing a partner from among two or more similarly-distant candidates. Classical spatial sensing paradigms that integrate spatial information to extract a single "upgradient" direction are poorly suited to this task, as the presence of two or more nearby 
chemoattractant sources may create a weak or even non-existent net gradient. The task of picking just one of the potential partners is accomplished by the coincidence-detection feature of exploratory polarization: stabilization of the polarity site only occurs when the partners' polarity sites happen to align (Fig. 1D). By including this temporal aspect in the partner search process, the cells can avoid the potential paralysis that could ensue from access to two or more equally attractive partners. We note that this partner selection task occurs not only in mating, but also more broadly in multicellular contexts that involve focal cell-cell junctions like synapses.

A potential problem with exploratory polarization stems from the observation that during the indecisive phase, cells frequently developed two or more transient polarity sites. In principle, then, a cell could end up with two polarity sites each oriented toward a different partner, leading to double mating. How cells avoid this problem poses an interesting question for future investigation.

\section{Acknowledgements:}

We thank Stefano Di Talia, Masayuki Onishi, and Amy Gladfelter, as well as members of the Lew lab for stimulating conversations and comments on the manuscript. M.R.C-C. was a Howard Hughes Medical Institute Gilliam Fellow and received a Graduate Diversity Enrichment Program Award from the Burroughs Wellcome Fund. This work was funded by NIH/NIGMS grants R35GM127145 to T.C.E. and R01GM103870 and R35GM122488 to D.J.L. 
MATERIALS AND METHODS

411 Table S1. Yeast and plasmid strains and genotypes

\begin{tabular}{|c|c|c|}
\hline Yeast strain & Relevant genotype & Source \\
\hline DLY8503 & MAT $\alpha$ SPA2-mCherry:KAN ${ }^{R}$ & This study \\
\hline DLY9069 & MATa BEM1-GFP:LEU2 & (Howell et al., 2009) \\
\hline DLY9070 & MAT $\alpha$ BEM1-GFP:LEU2 & (Kozubowski et al., 2008) \\
\hline DLY12943 & MATa BEM1-tdTomato:HIS3 & (Henderson et al., 2019) \\
\hline DLY12944 & MATa BEM1-tdTomato:HIS3 & This study \\
\hline DLY13771 & MATa BEM1-tdTomato:HIS3 ura3:GFP-SEC4:URA3 & (Henderson et al., 2019) \\
\hline DLY14364 & MATa STE20-GFP:HIS3 & This study \\
\hline DLY14413 & MATa STE20-tdTomato:HYG ${ }^{R}$ & This study \\
\hline DLY20712 & MATa SPA2-mCherry:KANR STE2-sfGFP:URA3 & This study \\
\hline DLY22243 & MATa BEM1-tdTomato:HIS3 STE2-sfGFP:URA3 & (Henderson et al., 2019) \\
\hline DLY22340 & MATa BEM1-tdTomato:HIS3 & (Henderson et al., 2019) \\
\hline DLY22355 & MATa BEM1-tdTomato STE6-sfGFP:KAN ${ }^{R}$ & This study \\
\hline DLY22797 & MATa BEM1-GFP:LEU2 cdc24-m1 (unmarked) rsr1D:HIS3 & This study \\
\hline DLY23256 & $\begin{array}{l}\text { MATa BEM1-tdTomato:HIS3 ura3:ste2O(DCRIB):URA3 } \\
\text { cdc24-4 }{ }^{\text {ts }} \text { (unmarked) WHI5-GFP:HIS5 }\end{array}$ & This study \\
\hline DLY23351 & $\begin{array}{l}\text { MATa BEM1-tdTomato:HIS3 GAL1p-PSR1(1-28)-GFP- } \\
\text { CDC24 }{ }^{38 A}: \text { LEU2 GAL-4BD-hER-VP16:URA3 WHI5-GFP:HIS5 }\end{array}$ & This study \\
\hline DLY23354 & MATa BEM1-tdTomato:HIS3 GFP-STE4 (unmarked) & This study \\
\hline DLY23612 & 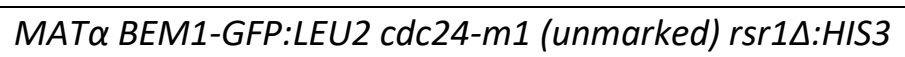 & This study \\
\hline
\end{tabular}

412

\begin{tabular}{|l|l|l|}
\hline Plasmid & Relevant genotype & Source \\
\hline DLB52 & $p F A 6 a-G F P(S 65 T)-H I S 3 M X 6$ & (Bähler et al., 1998) \\
\hline DLB3156 & $p R S 414 c d c 24-m 1$ & (Nern and Arkowitz, 1998) \\
\hline DLB4171 & $p R S 41 N-G F P-S T E 4$ & This study \\
\hline DLB4254 & $p$ RSII306-Ste4prom-GFP-Ste4(1-194) & This study \\
\hline DLB4292 & $p$ FA6a-link-yoSuperfolderGFP-Kan & (Lee et al., 2013) \\
\hline DLB4435 & $p R S 306-c d c 24-m 1: U R A 3$ & This study \\
\hline
\end{tabular}

414 Yeast strains and plasmids. Strains were constructed using standard molecular biology techniques.

415 Yeast strains used in this study (Table S1) were generated in the YEF473 background (his3- $\Delta 200$ leu2- $\Delta 1$

416 lys2-801 trp1- $\triangle 63$ ura3-52) (Bi and Pringle, 1996). The following alleles were previously described: 
BEM1-GFP:LEU2 (Kozubowski et al., 2008), BEM1-tdTomato:HIS3 (Howell et al., 2012), SPA2$m$ Cherry:KAN ${ }^{R}$ (Howell et al., 2009), GFP-SEC4:URA3 (Chen et al., 2012), STE20-GFP:HIS3 and ura3:ste20(DCRIB):URA3 (Moran et al., 2019), STE2-sfGFP:URA3 (Henderson et al., 2019), rsr1A:HIS3 (Schenkman et al., 2002), and GAL1p-PSR1(1-28)-GFP-CDC24 ${ }^{38 A}:$ LEU2 (Woods et al., 2015).

WHI5-GFP:S.p.HIS5 (Doncic et al., 2011) and STE6-SfGFP:KAN ${ }^{R}$ were constructed using methods described previously (Longtine et al., 1998) with DLB52 (pFA6a-GFP(S65T)-S.p.HIS5MX6; Addgene plasmid \#41598) and DLB4292 (pFA6a-link-yoSuperfolderGFP-Kan; Addgene plasmid \#44901) as templates.

GFP-STE4 was constructed in the YEF background by a pop-in, pop-out strategy. First, GFP-STE4 was PCR-amplified from a strain derived from RDY126 (Suchkov et al., 2010). This fragment was inserted into pRS41N (Taxis and Knop, 2006) using Apal and Notl, producing DLB4171 ( $p R S 41 N$-GFP-STE4). DLB4171 was digested with HindIII and Apal to release a fragment containing the STE4 promoter, GFP, and bp 1194 of the ORF. This fragment was inserted into DLB212 ( $p R S I I 306:$ a URA3-marked integrating plasmid) to produce DLB4254 ( $p R S I I 306-S t e 4 p r o m-G F P-S t e 4(1-194)$ ). DLB4254 was partially digested with Pstl to target integration to the STE4 locus of a diploid from the YEF background. Haploid segregants containing STE4(1-194), URA3 marker, and GFP-STE4 at the STE4 locus were plated on medium containing 5fluoroorotic acid to select for colonies in which recombination occurred between the promoter of the STE4 fragment and the promoter of GFP-STE4, removing the URA3 marker and leaving GFP-STE4 as a precise replacement of the endogenous STE4.

To introduce the $c d c 24-4$ allele into the YEF473 strain background, we first deleted one copy of CDC24 in a diploid strain using the HIS3 marker. A centromeric URA3-marked plasmid carrying wildtype CDC24 was transformed into the strain, and following sporulation and tetrad dissection a haploid cdc24::HIS3 strain carrying the plasmid was selected. cdc24-4 was amplified by PCR from a strain derived from JPT19-H01 (Sloat et al., 1981), and used to replace the cdc24::HIS3 allele by homologous recombination, followed by selection on medium containing 5 -fluoroorotic acid to obtain colonies without the plasmid.

The $c d c 24-m 1$ allele was amplified by PCR from $p R S 414-c d c 24-m 1$ (Nern and Arkowitz, 1998) and cloned into pRS306 to produce DLB4435 ( $p R S 306-c d c 24-m 1$ ). DLB4435 was digested with BspEl to target integration at the $C D C 24$ promoter, yielding a locus where the URA3 gene is inserted between the $c d c 24-m 1$ allele and wildtype CDC24. Haploid MATa segregants were grown on medium containing 5fluoroorotic acid to select for recombination between $c d c 24-m 1$ and $C D C 24$. Recombinants containing $c d c 24-m 1$ were identified by phenotyping (morphology when treated with pheromone) and confirmed by sequencing.

Live-cell microscopy. Cells were grown in complete synthetic medium (CSM; MP Biomedicals, LLC, Solon, $\mathrm{OH}, \mathrm{USA}$ ) with $2 \%$ dextrose (Macron, Center Valley, PA, USA) overnight at $30^{\circ} \mathrm{C}$ to mid-log phase $\left(10^{6}-10^{7}\right.$ cells $\left./ \mathrm{ml}\right)$. Cultures of opposite mating type strains were mixed to obtain a 1:1 cell ratio, centrifuged to concentrate the cells, and mounted on CSM-dextrose slabs solidified with $2 \%$ agarose (Hoefer, Holliston, MA, USA) and sealed with petroleum jelly. For pheromone "confusion" experiments, cells were imaged on a slab containing $10 \mu \mathrm{M} \alpha$-factor (Genway Biotech, San Diego, CA, USA). GAL1p$M T-C D C 24^{38 A}$ expression was induced in dextrose medium by adding $\beta$-estradiol (Sigma-Aldrich, St. Louis, MO, USA) to the medium to a final concentration of $20 \mathrm{nM}$, incubating for $2 \mathrm{~h}$, and imaging on a slab containing $20 \mathrm{nM} \beta$-estradiol (the strains contain an artificial transcription factor, GAL-4BD-hER$V P 16$, that induces the GAL1 promoter in response to $\beta$-estradiol). For $c d c 24-4^{\text {ts }}$ strains, cells were grown overnight at $24^{\circ} \mathrm{C}$ and shifted to $37^{\circ} \mathrm{C}$ for $2 \mathrm{~h}$ before imaging. For cells that were arrested in $\mathrm{G} 1(M T$ $C D C 24^{38 A}$ or $\left.c d c 24-4^{t s}\right), \alpha$-factor was added to a final concentration of $10 \mu \mathrm{M}$, and cells were incubated for $2 \mathrm{~h}$ before imaging on a slab containing $10 \mu \mathrm{M} \alpha$-factor. Imaging was performed in a temperaturecontrolled chamber at $30^{\circ} \mathrm{C}, 35^{\circ} \mathrm{C}$ or $37^{\circ} \mathrm{C}$ as indicated. 
Images were acquired with an Andor Revolution XD spinning disk confocal microscope (Andor Technology, Concord, MA, USA) with a CSU-X1 5,000-rpm confocal scanner unit (Yokogawa, Tokyo, Japan) and a UPLSAPO 100×/1.4 oil-immersion objective (Olympus, Tokyo, Japan), controlled by MetaMorph software (Molecular Devices, San Jose, CA, USA). Images were captured by an iXon3 897 EM-CCD camera with 1.2x auxiliary magnification (Andor Technology).

Images were acquired in z-stacks ( $150.47-\mu \mathrm{m}$ steps) at 2-min intervals. Laser power varied by experiment but was set to levels that produced bright signals with minimal bleaching during the movie: $8-15 \%(488 \mathrm{~nm})$ and $10-15 \%(561 \mathrm{~nm})$ of maximal output. EM gain was 200, and exposure time was 250 ms. Images were denoised with the ImageJ Hybrid 3D Median Filter plug-in (2007), created by Christopher Philip Mauer and Vytas Bindokas. Images are maximum projections except for MT-CDC24 ${ }^{38 A}$ medial plane image, as indicated. Scaling of images was always matched for experimental and relevant control conditions.

Ste20 initial orientation analysis. From mating movies, we identified all cells in G1. We segmented each cell into four quadrants (one proximal, one distal, and two medial; Fig. $2 A$ ), visually assigned the orientation of each cell's initial Ste20 polarity site to a quadrant, and calculated the fraction of initial sites that formed in each quadrant. For the subpopulation analyses, cells were considered either "adjacent" to a potential partner in G1 or "isolated" (i.e. not adjacent).

Colocalization analysis. From mating movies, we identified all cells in $\mathrm{G} 1$ that were adjacent to at least one potential G1-phase partner. For individual cells, we identified time points in which a clear localized Bem1 signal was present and scored the Ste2, Ste4, Sec4, or Ste6 signal as "colocalized" if the protein of interest was concentrated in the same area as Bem1 or "not colocalized" otherwise. For each pair of proteins, all time points were summed to calculate an overall colocalization frequency.

Mating efficiency. Mating efficiencies were calculated from mating movies. We tracked all cells in G1 that were adjacent to at least one potential G1-phase partner (i.e. "available" to mate) during a 2-h movie and scored them as "mated" or "not mated." Cells whose potential partners mated with another cell and cells that were available to mate only during the last 20 min were excluded from the sample. For each movie, three stage positions (i.e. technical replicates) were counted and summed to determine the fraction mated out of all available to mate ("mating efficiency").

Budding index. Budding indices were calculated from mating movies. Using the appearance of Bem1GFP or Bem1-tdTomato at the neck as a marker of G1, we first calculated the duration of G1 for all wildtype $\alpha$-cells that mated (mutants were a-cells) and determined the third quartile of that value (70 min). We then tracked all cells in G1 that were adjacent to at least one potential G1-phase partner (i.e. "available" to mate) for $70 \mathrm{~min}$, noting whether they budded, mated, or remained arrested. The fraction of cells that budded was the budding index.

Spatial autocorrelation analysis. The image processing toolbox in MATLAB 2019a was used to develop a custom tool to track individual cells during the mating period and determine commitment to a partner in an unbiased way. From mating movies, we identified wildtype $\alpha$-cells (BEM1-GFP or BEM1-tdTomato) that were available to mate with a-cell partners. We circumscribed the wildtype cells at several time points throughout the movie, beginning at $\mathrm{G} 1$ and ending either at the time point preceding fusion (for cells that mated) or the end of the movie (for cells that did not mate). Using linear interpolation, the outlines were deformed over time to accommodate changes in cell morphology and position. In this manner, we obtained cell outlines between the marked time points, enabling continuous tracking of each cell during the mating period. 
506

507

508

509

510

511

512

513

514

515

516

517

518

519

520

521

522

523

524

525

526

527

528

529

530

531

532

533

534

535

536

537

538

539

The spatial array of intracellular Bem1 signal was extracted at each time point, and the correlation between arrays at adjacent time points was calculated ("spatial autocorrelation"), using the following formula:

$$
r(t)=\frac{\operatorname{cov}(C(t), C(t+1))}{\sigma_{C(t)} \sigma_{C(t+1)}}
$$

where $r$ is Pearson's coefficient, cov is covariance, $C$ is an array containing indexed fluorescence data, $t$ is time point, and $\sigma_{C}$ is the standard deviation of the array $C$. The two arrays $C(t)$ and $C(t+1)$ were obtained by using a union of the outlines at time points $t$ and $t+1$ to ensure that spatial overlap was continuous.

During the indecisive period, $r$ is relatively low, but at commitment, $r$ is relatively high. To determine a threshold of $r$ that indicates commitment, we performed a sweep through different threshold values for a set of cells for which an experienced rater had already judged the time of commitment. A threshold value was selected to minimize discrepancies (either early or late judgments) between the automated and the human rater. The code used for this analysis can be found at: https://github.com/DebrajGhose/Exploratory-polarization-yeast

Statistics. Except for spatial autocorrelation analysis, statistical G-tests of goodness-of-fit were used to compare groups (McDonald, 2014).

\section{Calculation of pheromone concentrations expected for global and local secreting cells.}

To gain insight into the types of gradients expected from global and local secreting cells, we considered the gradient generated by a spherical emitter centered at the origin (Rappaport and Barkai, 2012). For this case, the pheromone gradient can be found by solving Laplace's equation using spherical coordinates. The r-coordinate satisfies the equation:

$$
\text { unit area) at the surface of the sphere }(r=R)
$$

The boundary conditions are constant flux density J (number of molecules released per unit time per

$$
\frac{\partial\left(\frac{r^{2} \partial C}{\partial r}\right)}{\partial r}=0
$$

and the concentration vanishes as $r \rightarrow \infty$. With these boundary conditions, the concentration takes the

and the concent
following form:

$$
-D\left[\frac{\partial C}{\partial r}\right]_{r=R}=J
$$

In terms of the total secretion rate $\mathrm{S}$, the above expression becomes

$$
C(r)=\frac{J R^{2}}{D r}
$$

$$
C(r)=\frac{\left(\frac{S}{4 \pi R^{2}}\right) R^{2}}{D r}=\frac{S}{4 \pi D r}
$$


If we assume a secretion rate of 1400 molecules/s and diffusion coefficient for pheromone molecules of $150 \mu \mathrm{m}^{2} / \mathrm{s}$, then the concentration at the surface of cell of radius $2.5 \mu \mathrm{m}$ is $\mathrm{C}(2.5)=0.3 \mathrm{molecules} / \mu \mathrm{m}^{3}=$ $0.5 \mathrm{nM}$. If we assume the localized emitter has a radius of $0.25 \mu \mathrm{m}$, then the concentration at the surface of the emitter is 10 times higher $\mathrm{C}(0.25)=5 \mathrm{nM}$. These results are consistent with the emitter alone results shown in Fig. S5B.

Simulations of pheromone landscape for two touching cells. Particle-based simulations of pheromone emission and diffusion were conducted using the Smoldyn software (v2.58) on Linux systems $(2.50 \mathrm{GHz}$ and $2.30 \mathrm{GHz}$ Intel processors, Longleaf cluster at UNC Chapel Hill, NC, USA (Andrews, 2017; Andrews and Bray, 2004). Code is available at https://github.com/mikepab/exploratory-polarization-yeast. Pheromone molecules were modeled as Brownian point particles with diffusion coefficient $D=150$ $\mu \mathrm{m}^{2} / \mathrm{s}$, and were removed at a spherical absorbing boundary $50 \mu \mathrm{m}$ from the origin. A mating pair was modeled as a two spheres, a receiver and emitter, centered at $( \pm(2.5+0.25 / 2) \mu \mathrm{m}, 0 \mu \mathrm{m}, 0 \mu \mathrm{m})$ with radius $2.5 \mu \mathrm{m}$. The system was first equilibrated for 5 seconds, after which coordinates were recorded every 0.1 ms timestep for 10 seconds. For each condition, $n=300$ realizations were conducted.

Vesicle emission events were simulated by repeated use of the Smoldyn command $\mathrm{cmd} @ \mathrm{t}$ pointsource pheromone $n \times y$ z. First, $t$ specifies the time of a single emission event; intervals between each emission were exponentially distributed:

$$
t_{k}=\sum_{i=0}^{k} \tau_{i} \text { for } \tau \sim \operatorname{Exponential}\left(1.188 \mathrm{~s}^{-1}\right)
$$

pheromone is a molecular species defined in the Smoldyn script, $\mathrm{n}$ is the number of molecules released per vesicle $(n=1663)$, and $x$ y $z$ are spatial coordinates of the vesicle event. In the local case, $(x=-$ $0.25 / 2+0.001 \mu \mathrm{m}, y=z=0 \mu \mathrm{m})$. In the global case, the spatial coordinates were obtained by uniform random sampling on a sphere centered at $(-(2.5+0.25 / 2) \mu \mathrm{m}, 0 \mu \mathrm{m}, 0 \mu \mathrm{m})$ with radius $2.5001 \mu \mathrm{m}$.

Single-molecule emission events were handled using the Smoldyn reaction surface= and reaction_production commands, with a release rate per timestep of $1 / 7.1429$ (yielding 1400 molecules per second at $0.1 \mathrm{~ms}$ timesteps). In the local case, the releasing surface was a sphere centered at $x=-0.25 / 2+0.001 \mu \mathrm{m}, y=z=0 \mu \mathrm{m}$ with a radius of $0.0005 \mu \mathrm{m}$. In the global case, the releasing surface was a sphere centered at $(-(2.5+0.25 / 2), 0,0) \mu \mathrm{m}$ with radius $2.5001 \mu \mathrm{m}$.

To validate the simulation setup, we set up simulations comparable to the analytic solution described above. The receiver was removed and pheromone profiles were measured as a function of distance to the emitter. The simulations were in good agreement with the analytic solution (Fig. S5B). filtered to only include pheromone within $0.25 \mu \mathrm{m}$ of the receiver surface. Then, a 3D angle between each molecule $\vec{r}_{i}$ and a reference vector $(\vec{v})$ was calculated:

$$
\theta_{i}=\arccos \left(\frac{\vec{r}_{i} \cdot \vec{v}}{\left\|\vec{r}_{i} \cdot \vec{v}\right\|}\right)
$$

The reference vector defines the patch under consideration (Fig 9A). For $0^{\circ}$, the closest patch to the emitter $\vec{v}=[-1,0,0]$. For the other patches, we rotate $[-1,0,0]$ by the desired angle $\theta_{\text {rot }}$.

$$
\vec{v}=\left[\begin{array}{ccc}
\cos \left(\theta_{\text {rot }}\right) & -\sin \left(\theta_{\text {rot }}\right) & 0 \\
\sin \left(\theta_{\text {rot }}\right) & \cos \left(\theta_{\text {rot }}\right) & 0 \\
0 & 0 & 1
\end{array}\right] \times\left[\begin{array}{c}
-1 \\
0 \\
0
\end{array}\right]
$$


To count molecules in each patch, we summed the number of points within $0^{\circ} \leq \theta_{i} \leq 30^{\circ}$. The volume of each patch is $V=\frac{2 \pi}{3}\left(2.75^{3}-2.5^{3}\right)\left(1-\cos \left(\frac{\pi}{6}\right)\right)$, which was used to convert molecules to nanomolar. Finally, a time-averaged pheromone concentration and coefficient of variation (CV) were calculated for each patch in each simulation, allowing us to compute a mean and standard error across simulations (Fig. 9D-G).

\section{Figure Legends}

Fig. 1. Pheromone landscapes encountered by yeast cells. (A) Stable unidirectional pheromone gradient, as generated by micropipet or microfluidics device. (B) Germinating spores in an ascus, where two potential partners (magenta) are expected to generate similar $\alpha$-factor gradients, making them equally attractive to the a-cells (green). (C) Microcolony containing a mixture of a-(green) and $\alpha$-cells (magenta). The proximity of multiple potential partners complicates the task of orienting toward a single partner. (D) Exploratory polarization model of partner selection. During the indecisive period (frames 1 and 2), diffusion of pheromone released at the $\alpha$-cell's (magenta) polarity site yields a low pheromone concentration at the a-cell's (green) polarity site. When the two polarity sites are apposed, the a-cell senses a high concentration of pheromone. Both cells sense and secrete pheromone, but for simplicity, only the a-cell's receptors and $\alpha$-cell's pheromone are shown.

Fig. 2. Behavior of mating cells before commitment to a partner. (A) Selected signaling and polarity activating the MAPK to promote downstream events, including polarization. (B) Cartoon depicting the quadrants (proximal, medial, distal) used to score the initial orientation of Ste20 relative to the motherbud neck. If Ste20 polarizes randomly, then we expect $25 \%$ proximal, $25 \%$ distal, and $50 \%$ medial. (C) MATa STE20-GFP (DLY14364) and MATa STE20-tdTomato (DLY14413) cells were mixed and imaged during mating. Inverted maximum-projection montages illustrate representative mother-daughter pairs. Top, Ste20-tdTomato formed clusters at medial (M) and proximal (P) sites. Bottom, a Ste20-GFP cluster formed distal (D) to the neck (yellow oval). (D) Initial orientation of Ste20 clusters from the mating mix in (C), and in subsets that were (adjacent) or were not (isolated) touching potential mating partners. *: goodness-of-fit test, $p=0.05$. (E) Cells harboring STE2-sfGFP and either BEM1-tdTomato (DLY22243) or SPA2-mCherry (DLY20712) were mixed with cells of the opposite mating type (BEM1-tdTomato, DLY22340 or SPA2-mCherry, DLY8503, respectively) and imaged during mating. Following Ste2 degradation, sfGFP accumulates in the vacuole (V). Ste2-sfGFP crescents gradually intensified in regions visited by polarity clusters. Blue arrowheads, accumulation of Spa2 or Bem1 at cytokinesis site; white arrowheads, polarity sites during indecisive phase; orange arrowheads, final polarity site. Cartoons summarize polarity behaviors. Scale bars: $5 \mu \mathrm{m}$.

Fig. 3. Localization of pheromone secretion, sensing, and signaling proteins during the indecisive subunit GFP-STE4 (DLY23354), secretory vesicle marker GFP-SEC4 (DLY13771), or a-factor transporter STE6-SfGFP (DLY22355) were imaged during mating. (A) Representative images show examples of the indicated probes during the indecisive period (left two images), in committed cells (comm) and just after fusion (fused). Internal signal in Ste2-sfGFP and Ste6-sfGFP strains is due to sfGFP accumulation in the vacuole (V) following Ste2/Ste6 degradation. For time points when cells had clusters of Bem1-tdTomato, the green probe was scored as either not colocalized (not coloc, blue arrowheads) or colocalized (coloc, orange arrowheads). Yellow oval: cytokinesis site. Orange dashed line: zygote. Scale bars: $5 \mu \mathrm{m}$. (B) The colocalization frequency during the indecisive phase, scored as illustrated in $(A)$, varied from cell to cell. Different cells had indecisive periods of different durations, and only some of the time points showed clear clusters of Bem1 for scoring. Y-axis: number of time points scored per cell. (C) Overall 
colocalization frequency (\% of time points during the indecisive phase that show colocalization of the indicated probe with the Bem1 signal). $n$, total number of time points scored.

Fig. 4. Wildtype cells do not commit to unpolarized partners. Selected time points from movies of mating mixes. Cartoons indicate cells in the selected montages at the start of the displayed imaging interval. B: bud. Yellow oval: mother-bud neck. White arrowhead: weak, mobile Bem1 cluster characteristic of indecisive cells, focusing on the magenta $(A, B)$ or green $(C, D)$ channel wildtype cells. Orange arrowheads: stably oriented Bem1 clusters characteristic of committed cells. Dashed outline: fused zygote. (A) MATa wildtype cells (BEM1-tdTomato, DLY12944) mixed with MATa wildtype cells (BEM1-GFP, DLY9069), imaged at $30^{\circ} \mathrm{C}$. (B) The same MAT $\alpha$ wildtype strain mixed with MATa cells harboring membrane-targeted, constitutively-active Cdc24 (MT-GFP-CDC24 ${ }^{38 A}$, DLY23351) that do not make polarity clusters and imaged at $30^{\circ} \mathrm{C}$. Two montages are shown. (C) MAT $\alpha$ wildtype cells (BEM1GFP, DLY9070) mixed with MATa wildtype cells (BEM1-tdTomato, DLY12943), imaged at $37^{\circ} \mathrm{C}$. (D) The same MAT $\alpha$ wildtype strain mixed with MATa cells harboring $c d c 24-4^{\text {ts }}$ (DLY23256, green nuclei indicate G1 cells), imaged at $35^{\circ} \mathrm{C}$. Two montages are shown. Scale bars: $5 \mu \mathrm{m}$.

Fig. 5. Scoring commitment and cell cycle arrest in mating mixes. (A) Cartoon illustrating spatial autocorrelation algorithm to score commitment. The spatial distribution of Bem1 pixel intensities in a cell of interest (magenta clusters) are compared at consecutive time points to yield a normalized correlation measure between 0 (no correlation) and 1 (perfect correlation). Strong and stably oriented polarity sites characteristic of committed cells $(3,4)$ yield a high correlation while weaker, mobile polarity sites characteristic of indecisive cells $(0,1,2)$ yield a low correlation. (B) Example spatial autocorrelation traces from wildtype cells mixed with either wildtype partners or the indicated nonclustering mutants as in Fig. 4. Horizontal yellow line: threshold autocorrelation used to call commitment. Purple vertical line: commitment time as scored visually. Wildtype cells attempting to mate with unpolarized mutants did not reach the threshold, even after $100 \mathrm{~min}$. (C) Wildtype cells adjacent to G1-phase cells of opposite mating type sometimes return to the cell cycle and form a bud. The percent of wildtype cells that budded was determined from the mating mixes with the indicated partners (genotypes as in Fig. 4 and 6).

Fig. 6. Wildtype cells do not commit to mutants with constitutively mobile polarity sites. (A-C) Selected time points from movies of mating mixes. Yellow oval: mother-bud neck. White arrowhead: weak mobile Bem 1 cluster characteristic of indecisive cells, focusing on the magenta $(A)$ or green $(B, C)$ channel wildtype cells. Orange arrowheads: stably oriented Bem1 clusters characteristic of committed cells. Dashed outline: fused zygote. (A) MATa wildtype cells (BEM1-tdTomato, DLY12944) were mixed with MATa mutants that form constitutively mobile polarity clusters (cdc24-m1 rsr1 $\triangle B E M 1-G F P$, DLY22797) and imaged at $30^{\circ} \mathrm{C}$. (B) MAT $\alpha$ wildtype cells (BEM1-GFP, DLY9070) were mixed with MATa wildtype cells (BEM1-tdTomato, DLY12943). Control mating mix in which mating type and fluorophore are switched relative to Fig. 4A. (C) MATa wildtype cells (BEM1-tdTomato, DLY12943) were mixed with MAT $\alpha$ mutants that form constitutively mobile polarity clusters (cdc24-m1 rsr1 $B E M 1-G F P$, DLY23612). (D) Spatial autocorrelation traces of representative wildtype cells mixed with cdc24-m1 rsr1 $\Delta$ cells from (A).

Fig. 7. Wildtype cells do not commit to mutants with stable but misoriented polarity sites. (A) Selected time points from movies of mating mixes. White arrowhead:weak mobile Bem 1 cluster characteristic of indecisive cells, focusing on the magenta channel wildtype cells. In the presence of $10 \mu \mathrm{M} \alpha$-factor, MATa cells (BEM1-GFP, DLY9069) polarize stably and form mating projections. When these projections are oriented away from the MAT $\alpha$ wildtype potential partner (BEM1-tdTomato, DLY12944), the partner forms polarity sites that remain indecisive. (B) Representative spatial autocorrelation traces of MAT $\alpha$ cells from (A). 
Fig. 8. Default mating requires fortuitous correct orientation by the "confused" partner. (A,B) Selected time points from movies of the same mating mixes as in Fig. 7. (A) Examples of successful mating. (B) Examples in which mating fails despite apparently correct orientation by the confused partner. (C) Representative spatial autocorrelation traces of MAT $\alpha$ cells that did (top three) or did not (bottom six) mate.

Fig. 9. Simulations of the pheromone receiver's landscape for two touching cells. (A) Model setup for emitter and receiver cells shown at scale. Seven patch positions on the receiver $\left(0^{\circ}\right.$ to $180^{\circ}$, changing colors) were used to measure local pheromone concentrations. (B) Local versus global secretion. In local secretion, pheromone was released just at the emitter pole abutting the receiver. In global secretion, pheromone was released uniformly just at the emitter surface. (C) Instantaneous pheromone concentration at different positions (color) near receiver's surface over time during local vesicle secretion. (D,E) Time-averaged pheromone concentration at different positions (color) on receiver's surface for both vesicle and single-molecule release. $(F, G)$ Coefficient of variation $(C V)$ for $(D, E)$. All bars show mean \pm s.e.m., $\mathrm{n}=300$ realizations.

\section{SUPPLEMENTARY FIGURE LEGENDS}

Fig. S1. Overexpression of membrane-targeted Cdc24 blocks polarization. Medial plane confocal images of cells induced to express membrane-targeted, phospho-site mutant GFP-CDC24 ${ }^{38 A}$ (MT-GFPCDC24 ${ }^{38 A}$ BEM1-tdTomato, DLY23351) and mixed with wildtype cells (BEM1-tdTomato, DLY12944). Scale bar: $5 \mu \mathrm{m}$.

Fig. S2. Threshold determination for spatial autocorrelation analyses. (A) The number of false negatives (in which the spatial autocorrelation trace did not cross the threshold but did commit as scored visually) and false positives (in which the spatial autocorrelation trace crossed the threshold $>4$ min before commitment as scored visually) as a function of commitment threshold for wildtype $x$ wildtype pairs at $30^{\circ} \mathrm{C}$. A threshold of 0.77 was selected (orange tick). (B) Similar analysis for wildtype $x$ wildtype pairs at $35^{\circ} \mathrm{C}$. A threshold of 0.44 was selected (orange tick).

Fig. S3. Spatial autocorrelation traces for cells at $30^{\circ} \mathrm{C}$. (A) Wildtype by wildtype mixes as in Fig. 4A. Traces begin at the time of the cell's entry into $\mathrm{G} 1$ and end at the time point preceding fusion. X-axis: Time (min). Y-axis: spatial autocorrelation (yellow line: commitment threshold). Commitment to a partner as determined visually (vertical purple line) or by crossing the threshold (dashed green line). (B) Similar analysis for wildtype cells mating with $M T-C d c 24^{38 A}$ partners as in Figure 4B.

Fig. S4. Spatial autocorrelation traces for cells at $35^{\circ} \mathrm{C}$. (A) Wildtype by wildtype mixes. Traces begin at the time of the cell's entry into $\mathrm{G} 1$ and end at the time point preceding fusion. $X$ axis: Time (min). $Y$ axis: spatial autocorrelation (yellow line: commitment threshold). Commitment to a partner as determined visually (vertical purple line) or by crossing the threshold (dashed green line). (B) Similar analysis for wildtype cells mating with cdc24-4ts partners as in Fig. 4D.

Figure S5. Validation of the pheromone simulations and additional detail. (A) Pheromone concentrations perceived at three different patches in a single simulation as in Fig. 9C, but zoomed in to show 0.1 second along the $x$-axis. (B) Simulations of the emitter alone, comparing concentrations in a spherical $250 \mathrm{~nm}$ shell (not a patch) at the indicated distance from the center of the emitter versus the steady-state analytic solution of the diffusion equation under equivalent conditions. Bars show mean \pm s.d., $\mathrm{n}=30$.

\section{MOVIE LEGENDS}


Movie 1. Mating between cells harboring STE20-GFP (DLY14364) and STE20-tdTomato (DLY14413). Denoised maximum projections. Time in h:min. White arrowheads: selected polarity sites; orange arrowhead: commitment; dashed orange outline: zygote. Scale bar: $5 \mu \mathrm{m}$.

Movie 2. Mating between cells harboring BEM1-GFP (DLY9069) and BEM1-tdTomato (DLY12944). Denoised maximum projections. Time in $\mathrm{h}: \mathrm{min}$. White arrowheads: selected polarity sites; orange arrowhead: commitment; dashed orange outline: zygote. Scale bar: $5 \mu \mathrm{m}$.

Movie 3. Unsuccessful mating attempt between cells harboring MT-GFP-CDC24 ${ }^{38 A}$ BEM1-tdTomato (DLY23351) and BEM1-tdTomato (DLY12944). Denoised maximum projections. Time in h:min. White arrowheads: initial polarity sites. Scale bar: $5 \mu \mathrm{m}$.

Movie 4. Mating between cells harboring BEM1-tdTomato (DLY12943) and BEM1-GFP (DLY9070). Denoised maximum projections. Time in $\mathrm{h}: \mathrm{min}$. White arrowheads: selected polarity sites; orange arrowhead: commitment; dashed orange outline: zygote. Scale bar: $5 \mu \mathrm{m}$.

Movie 5. Unsuccessful mating attempt between cells harboring cdc24-4ts (DLY23256) and BEM1-GFP (DLY9070). Denoised maximum projections. Time in h:min. White arrowheads: initial polarity sites. Scale bar: $5 \mu \mathrm{m}$.

Movie 6. Unsuccessful mating attempt between cells harboring cdc24-m1 rsr1 (DLY22797) and BEM1tdTomato (DLY12944). Denoised maximum projections. Time in h:min. White arrowheads: initial polarity sites. Scale bar: $5 \mu \mathrm{m}$.

Movie 7. Unsuccessful mating attempt between cells harboring BEM1-GFP (DLY9069, MATa, "confused") and BEM1-tdTomato (DLY12944, MAT $\alpha$, searching) plus $10 \mu \mathrm{M} \alpha$-factor. Denoised maximum projections. Time in h:min. White arrowheads: initial polarity sites. Scale bar: $5 \mu \mathrm{m}$.

Movie 8. Mating between cells harboring BEM1-GFP (DLY9069, MATa, "confused") and BEM1-tdTomato (DLY12944, MAT $\alpha$, searching) plus $10 \mu \mathrm{M} \alpha$-factor. Denoised maximum projections. Time in h:min. White arrowheads: selected polarity sites; orange arrowhead: commitment; dashed orange outline: zygote. Scale bar: $5 \mu \mathrm{m}$.

Movie 9. Unsuccessful mating attempt between cells harboring BEM1-GFP (DLY9069, MATa, "confused") and BEM1-tdTomato (DLY12944, MAT $\alpha$, searching) plus $10 \mu \mathrm{M} \alpha$-factor. Denoised maximum projections. Time in h:min. White arrowheads: selected polarity sites. Scale bar: $5 \mu \mathrm{m}$. 


\section{REFERENCES}

Adams, A.E., D.I. Johnson, R.M. Longnecker, B.F. Sloat, and J.R. Pringle. 1990. CDC42 and CDC43, two additional genes involved in budding and the establishment of cell polarity in the yeast Saccharomyces cerevisiae. The Journal of cell biology. 111:131-142.

Andrews, S.S. 2017. Smoldyn: particle-based simulation with rule-based modeling, improved molecular interaction and a library interface. Bioinformatics. 33:710-717.

Andrews, S.S., and D. Bray. 2004. Stochastic simulation of chemical reactions with spatial resolution and single molecule detail. Phys Biol. 1:137-151.

Arkowitz, R.A. 1999. Responding to attraction: Chemotaxis and chemotropism in Dictyostelium and yeast. Trends in cell biology. 9:20-27.

Atkins, B.D., S. Yoshida, K. Saito, C.F. Wu, D.J. Lew, and D. Pellman. 2013. Inhibition of Cdc42 during mitotic exit is required for cytokinesis. The Journal of cell biology. 202:231-240.

Ayscough, K.R., and D.G. Drubin. 1998. A role for the yeast actin cytoskeleton in pheromone receptor clustering and signalling. Current biology : CB. 8:927-930.

Bähler, J., J.Q. Wu, M.S. Longtine, N.G. Shah, A. McKenzie, 3rd, A.B. Steever, A. Wach, P. Philippsen, and J.R. Pringle. 1998. Heterologous modules for efficient and versatile PCR-based gene targeting in Schizosaccharomyces pombe. Yeast (Chichester, England). 14:943-951.

Bajaj, A., A. Celić, F.X. Ding, F. Naider, J.M. Becker, and M.E. Dumont. 2004. A fluorescent alpha-factor analogue exhibits multiple steps on binding to its $G$ protein coupled receptor in yeast. Biochemistry. 43:13564-13578.

Bellon, A., and F. Mann. 2018. Keeping up with advances in axon guidance. Current opinion in neurobiology. 53:183-191.

Bender, A., and J.R. Pringle. 1989. Multicopy suppression of the cdc24 budding defect in yeast by CDC42 and three newly identified genes including the ras-related gene RSR1. Proceedings of the National Academy of Sciences. 86:9976-9980.

Bendezu, F.O., and S.G. Martin. 2013. Cdc42 explores the cell periphery for mate selection in fission yeast. Current biology : CB. 23:42-47.

$\mathrm{Bi}, \mathrm{E}$. , and J.R. Pringle. 1996. ZDS1 and ZDS2, genes whose products may regulate Cdc42p in Saccharomyces cerevisiae. Molecular and cellular biology. 16:5264-5275.

Brett, M.E., R. DeFlorio, D.E. Stone, and D.T. Eddington. 2012. A microfluidic device that forms and redirects pheromone gradients to study chemotropism in yeast. Lab Chip. 12:3127-3134.

Butty, A.C., P.M. Pryciak, L.S. Huang, I. Herskowitz, and M. Peter. 1998. The role of Far1p in linking the heterotrimeric $\mathrm{G}$ protein to polarity establishment proteins during yeast mating. Science. 282:1511-1516.

Chant, J., and I. Herskowitz. 1991. Genetic control of bud site selection in yeast by a set of gene products that constitute a morphogenetic pathway. Cell. 65:1203-1212.

Chen, H., C.C. Kuo, H. Kang, A.S. Howell, T.R. Zyla, M. Jin, and D.J. Lew. 2012. Cdc42p regulation of the yeast formin Bni1p mediated by the effector Gic2p. Molecular biology of the cell. 23:3814-3826.

Dohlman, H.G., and J.W. Thorner. 2001. Regulation of G protein-initiated signal transduction in yeast: Paradigms and principles. Annu Rev Biochem. 70:703-754.

Doncic, A., M. Falleur-Fettig, and Jan M. Skotheim. 2011. Distinct interactions select and maintain a specific cell fate. Molecular cell. 43:528-539.

Dorer, R., C. Boone, T. Kimbrough, J. Kim, and L.H. Hartwell. 1997. Genetic analysis of default mating behavior in Saccharomyces cerevisiae. Genetics. 146:39-55.

Dorer, R., P.M. Pryciak, and L.H. Hartwell. 1995. Saccharomyces cerevisiae cells execute a default pathway to select a mate in the absence of pheromone gradients. The Journal of cell biology. 131:845-861. 
Dyer, J.M., N.S. Savage, M. Jin, T.R. Zyla, T.C. Elston, and D.J. Lew. 2013. Tracking shallow chemical gradients by actin-driven wandering of the polarization site. Current biology : CB. 23:32-41.

Hao, N., S. Nayak, M. Behar, R.H. Shanks, M.J. Nagiec, B. Errede, J. Hasty, T.C. Elston, and H.G. Dohlman. 2008. Regulation of cell signaling dynamics by the protein kinase-scaffold Ste5. Molecular cell. 30:649-656.

Hegemann, B., and M. Peter. 2017. Local sampling paints a global picture: Local concentration measurements sense direction in complex chemical gradients. BioEssays : news and reviews in molecular, cellular and developmental biology. 39.

Hegemann, B., M. Unger, Sung S. Lee, I. Stoffel-Studer, J. van den Heuvel, S. Pelet, H. Koeppl, and M. Peter. 2015. A cellular system for spatial signal decoding in chemical gradients. Developmental cell. 35:458-470.

Henderson, N.T., M. Pablo, D. Ghose, M.R. Clark-Cotton, T.R. Zyla, J. Nolen, T.C. Elston, and D.J. Lew. 2019. Ratiometric GPCR signaling enables directional sensing in yeast. PLoS Biol. 17:e3000484e3000484.

Higashiyama, T., and H. Takeuchi. 2015. The mechanism and key molecules involved in pollen tube guidance. Annual review of plant biology. 66:393-413.

Howell, Audrey S., M. Jin, C.-F. Wu, Trevin R. Zyla, Timothy C. Elston, and Daniel J. Lew. 2012. Negative feedback enhances robustness in the yeast polarity establishment circuit. Cell. 149:322-333.

Howell, A.S., N.S. Savage, S.A. Johnson, I. Bose, A.W. Wagner, T.R. Zyla, H.F. Nijhout, M.C. Reed, A.B. Goryachev, and D.J. Lew. 2009. Singularity in polarization: Rewiring yeast cells to make two buds. Cell. 139:731-743.

Ismael, A., and D.E. Stone. 2017. Yeast chemotropism: A paradigm shift in chemical gradient sensing. Cellular logistics. 7:e1314237.

Jackson, C.L., and L.H. Hartwell. 1990a. Courtship in S. cerevisiae: Both cell types choose mating partners by responding to the strongest pheromone signal. Cell. 63:1039-1051.

Jackson, C.L., and L.H. Hartwell. 1990b. Courtship in Saccharomyces cerevisiae: An early cell-cell interaction during mating. Molecular and cellular biology. 10:2202-2213.

Jenness, D.D., A.C. Burkholder, and L.H. Hartwell. 1983. Binding of $\alpha$-factor pheromone to yeast a cells: Chemical and genetic evidence for an $\alpha$-factor receptor. Cell. 35:521-529.

Jenness, D.D., and P. Spatrick. 1986. Down regulation of the $\alpha$-factor pheromone receptor in S. cerevisiae. Cell. 46:345-353.

Jin, M., B. Errede, M. Behar, W. Mather, S. Nayak, J. Hasty, H.G. Dohlman, and T.C. Elston. 2011. Yeast dynamically modify their environment to achieve better mating efficiency. 4:ra54-ra54.

Johnson, J.M., M. Jin, and D.J. Lew. 2011. Symmetry breaking and the establishment of cell polarity in budding yeast. Current opinion in genetics \& development. 21:740-746.

Kelley, J.B., G. Dixit, J.B. Sheetz, S.P. Venkatapurapu, T.C. Elston, and H.G. Dohlman. 2015. RGS proteins and septins cooperate to promote chemotropism by regulating polar cap mobility. Current biology : CB. 25:275-285.

Kozubowski, L., K. Saito, J.M. Johnson, A.S. Howell, T.R. Zyla, and D.J. Lew. 2008. Symmetry-breaking polarization driven by a Cdc42p GEF-PAK complex. Current biology : CB. 18:1719-1726.

Kuo, C.-C., N.S. Savage, H. Chen, C.-F. Wu, T.R. Zyla, and D.J. Lew. 2014. Inhibitory GEF phosphorylation provides negative feedback in the yeast polarity circuit. Current biology : CB. 24:753-759.

Lee, S., W.A. Lim, and K.S. Thorn. 2013. Improved blue, green, and red fluorescent protein tagging vectors for S. cerevisiae. PloS one. 8:e67902.

Lee, S.S., P. Horvath, S. Pelet, B. Hegemann, L.P. Lee, and M. Peter. 2012. Quantitative and dynamic assay of single cell chemotaxis. Integr Biol (Camb). 4:381-390. 
Longtine, M.S., A. McKenzie, 3rd, D.J. Demarini, N.G. Shah, A. Wach, A. Brachat, P. Philippsen, and J.R. Pringle. 1998. Additional modules for versatile and economical PCR-based gene deletion and modification in Saccharomyces cerevisiae. Yeast (Chichester, England). 14:953-961.

Martin, S.G. 2019. Molecular mechanisms of chemotropism and cell fusion in unicellular fungi. 132:jcs230706.

McClure, A.W., K.C. Jacobs, T.R. Zyla, and D.J. Lew. 2018. Mating in wild yeast: Delayed interest in sex after spore germination. Molecular biology of the cell:mbcE18080528.

McClure, Allison W., M. Minakova, Jayme M. Dyer, Trevin R. Zyla, Timothy C. Elston, and Daniel J. Lew. 2015. Role of polarized G protein signaling in tracking pheromone gradients. Developmental cell. 35:471-482.

McDonald, J.H. 2014. Handbook of Biological Statistics. Sparky House Publishing, Baltimore, Maryland. Merlini, L., O. Dudin, and S.G. Martin. 2013. Mate and fuse: How yeast cells do it. Open Biology. 3.

Merlini, L., B. Khalili, F.O. Bendezu, D. Hurwitz, V. Vincenzetti, D. Vavylonis, and S.G. Martin. 2016. Local pheromone release from dynamic polarity sites underlies cell-cell pairing during yeast mating. Current biology : CB. 26:1117-1125.

Michaelis, S., and J. Barrowman. 2012. Biogenesis of the Saccharomyces cerevisiae pheromone a-factor, from yeast mating to human disease. Microbiology and molecular biology reviews : MMBR. 76:626-651.

Moore, S.A. 1983. Comparison of dose-response curves for alpha factor-induced cell division arrest, agglutination, and projection formation of yeast cells. Implication for the mechanism of alpha factor action. The Journal of biological chemistry. 258:13849-13856.

Moore, T.I., C.-S. Chou, Q. Nie, N.L. Jeon, and T.-M. Yi. 2008. Robust spatial sensing of mating pheromone gradients by yeast cells. PloS one. 3:e3865.

Moore, T.I., H. Tanaka, H.J. Kim, N.L. Jeon, and T.-M. Yi. 2013. Yeast G-proteins mediate directional sensing and polarization behaviors in response to changes in pheromone gradient direction. 24:521-534.

Moran, K.D., H. Kang, A.V. Araujo, T.R. Zyla, K. Saito, D. Tsygankov, and D.J. Lew. 2019. Cell-cycle control of cell polarity in yeast. The Journal of cell biology. 218:171-189.

Moskow, J.J., A.S. Gladfelter, R.E. Lamson, P.M. Pryciak, and D.J. Lew. 2000. Role of Cdc42p in pheromone-stimulated signal transduction in Saccharomyces cerevisiae. Molecular and cellular biology. 20:7559-7571.

Nern, A., and R.A. Arkowitz. 1998. A GTP-exchange factor required for cell orientation. Nature. 391:195198.

Nern, A., and R.A. Arkowitz. 1999. A Cdc24p-Far1p-Gbetagamma protein complex required for yeast orientation during mating. The Journal of cell biology. 144:1187-1202.

Nern, A., and R.A. Arkowitz. 2000. G proteins mediate changes in cell shape by stabilizing the axis of polarity. Molecular cell. 5:853-864.

Nichols, J.M., D. Veltman, and R.R. Kay. 2015. Chemotaxis of a model organism: Progress with Dictyostelium. Curr Opin Cell Biol. 36:7-12.

Paliwal, S., P.A. Iglesias, K. Campbell, Z. Hilioti, A. Groisman, and A. Levchenko. 2007. MAPK-mediated bimodal gene expression and adaptive gradient sensing in yeast. Nature. 446:46-51.

Park, H.O., and E. Bi. 2007. Central roles of small GTPases in the development of cell polarity in yeast and beyond. Microbiology and molecular biology reviews : MMBR. 71:48-96.

Pruyne, D., A. Legesse-Miller, L. Gao, Y. Dong, and A. Bretscher. 2004. Mechanisms of polarized growth and organelle segregation in yeast. Annu Rev Cell Dev Biol. 20:559-591.

Rappaport, N., and N. Barkai. 2012. Disentangling signaling gradients generated by equivalent sources. Journal of Biological Physics. 38:267-278. 
Raths, S.K., F. Naider, and J.M. Becker. 1988. Peptide analogues compete with the binding of alphafactor to its receptor in Saccharomyces cerevisiae. The Journal of biological chemistry. 263:17333-17341.

Rogers, D.W., E. McConnell, and D. Greig. 2012. Molecular quantification of Saccharomyces cerevisiae $\alpha$ pheromone secretion. FEMS Yeast Res. 12:668-674.

Sarris, M., and M. Sixt. 2015. Navigating in tissue mazes: Chemoattractant interpretation in complex environments. Current Opinion in Cell Biology. 36:93-102.

Schenkman, L.R., C. Caruso, N. Pagé, and J.R. Pringle. 2002. The role of cell cycle-regulated expression in the localization of spatial landmark proteins in yeast. The Journal of cell biology. 156:829-841.

Segall, J.E. 1993. Polarization of yeast cells in spatial gradients of alpha mating factor. Proceedings of the National Academy of Sciences of the United States of America. 90:8332-8336.

Simon, M.N., C. De Virgilio, B. Souza, J.R. Pringle, A. Abo, and S.I. Reed. 1995. Role for the Rho-family GTPase Cdc42 in yeast mating-pheromone signal pathway. Nature. 376:702-705.

Sloat, B.F., A. Adams, and J.R. Pringle. 1981. Roles of the CDC24 gene product in cellular morphogenesis during the Saccharomyces cerevisiae cell cycle. The Journal of cell biology. 89:395-405.

Suchkov, D.V., R. DeFlorio, E. Draper, A. Ismael, M. Sukumar, R. Arkowitz, and D.E. Stone. 2010. Polarization of the yeast pheromone receptor requires its internalization but not actindependent secretion. Molecular biology of the cell. 21:1737-1752.

Taxis, C., P. Keller, Z. Kavagiou, L.J. Jensen, J. Colombelli, P. Bork, E.H.K. Stelzer, and M. Knop. 2005. Spore number control and breeding in Saccharomyces cerevisiae: A key role for a self-organizing system. The Journal of cell biology. 171:627-640.

Taxis, C., and M. Knop. 2006. System of centromeric, episomal, and integrative vectors based on drug resistance markers for Saccharomyces cerevisiae. BioTechniques. 40:73-78.

Valtz, N., M. Peter, and I. Herskowitz. 1995. FAR1 is required for oriented polarization of yeast cells in response to mating pheromones. The Journal of cell biology. 131:863-873.

Vasen, G., P. Dunayevich, and A. Colman-Lerner. 2020. Mitotic and pheromone-specific intrinsic polarization cues interfere with gradient sensing in Saccharomyces cerevisiae. Proceedings of the National Academy of Sciences. 117:6580.

Wang, X., W. Tian, B.T. Banh, B.-M. Statler, J. Liang, and D.E. Stone. 2019. Mating yeast cells use an intrinsic polarity site to assemble a pheromone-gradient tracking machine. The Journal of cell biology:jcb.201901155.

Woods, B., C.-C. Kuo, C.-F. Wu, T.R. Zyla, and D.J. Lew. 2015. Polarity establishment requires localized activation of Cdc42. The Journal of cell biology. 211:19-26.

Yi, T.M., H. Kitano, and M.I. Simon. 2003. A quantitative characterization of the yeast heterotrimeric G protein cycle. Proceedings of the National Academy of Sciences of the United States of America. 100:10764-10769.

Zhao, Z.S., T. Leung, E. Manser, and L. Lim. 1995. Pheromone signalling in Saccharomyces cerevisiae requires the small GTP-binding protein Cdc42p and its activator CDC24. Molecular and cellular biology. 15:5246-5257. 
A
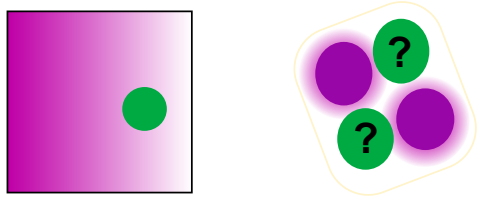

C

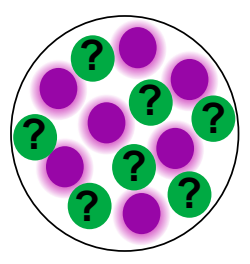

D
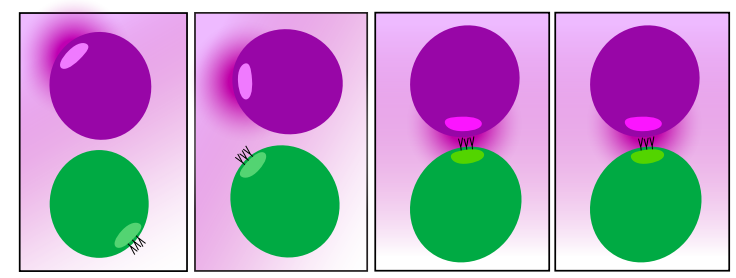

Time

\section{Indecisive}

Polarity sites

weak and transient
Fig. 1. Pheromone landscapes encountered by yeast cells. (A) Stable unidirectional pheromone gradient, as generated by micropipet or microfluidics device. (B) Germinating spores in an ascus, where two potential partners (magenta) are expected to generate similar a-factor gradients, making them equally attractive to the a-cells (green). (C) Microcolony containing a mixture of a-(green) and $\alpha$-cells (magenta). The proximity of multiple potential partners complicates the task of orienting toward a single partner. (D) Exploratory polarization model of partner selection. During the indecisive period (frames 1 and 2 ), diffusion of pheromone released at the $\alpha$-cell's (magenta) polarity site yields a low pheromone concentration at the a-cell's (green) polarity site. When the two polarity sites are apposed, the a-cell senses a high concentration of pheromone. Both cells sense and secrete pheromone, but for simplicity, only the a-cell's receptors and $\alpha$-cell's pheromone are shown. 
bioRxiv preprint doi: https://doi.org/10.1101/2020.09.07.285965; this version posted September 7, 2020. The copyright holder for this preprint Figure (whigh was not certified by peer review) is the author/funder, who has granted bioRxiv a license to display the preprint in perpetuity. It is made
available under aCC-BY-NC-ND 4.0 International license.

A

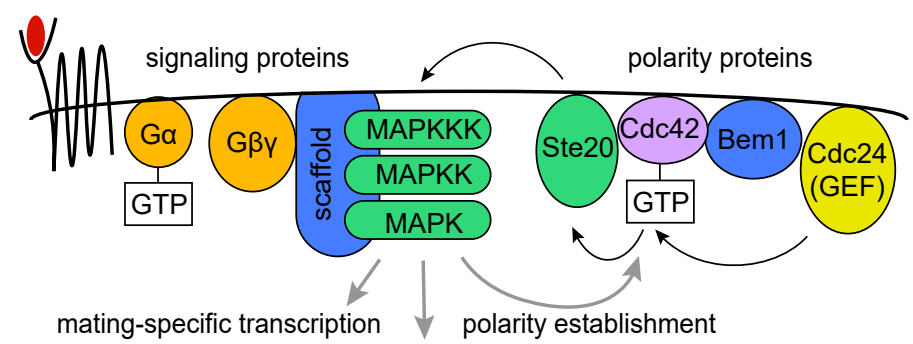

B

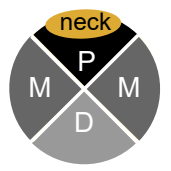

C

Ste20-tdTomato
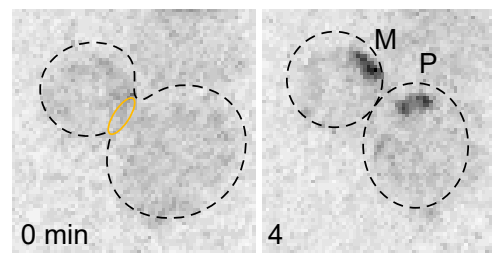

Ste20-GFP
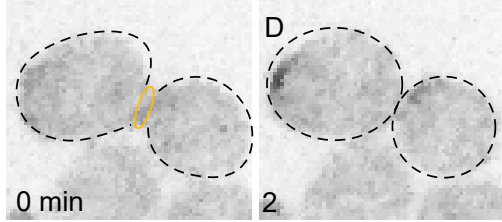

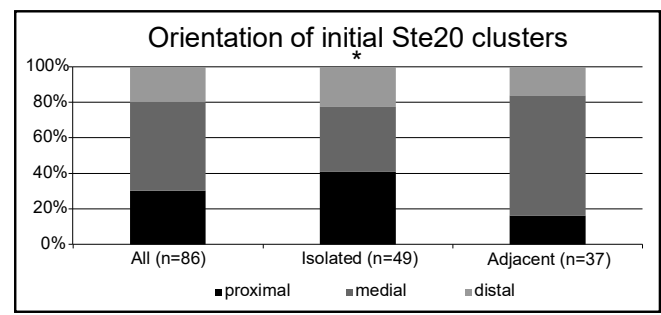

E
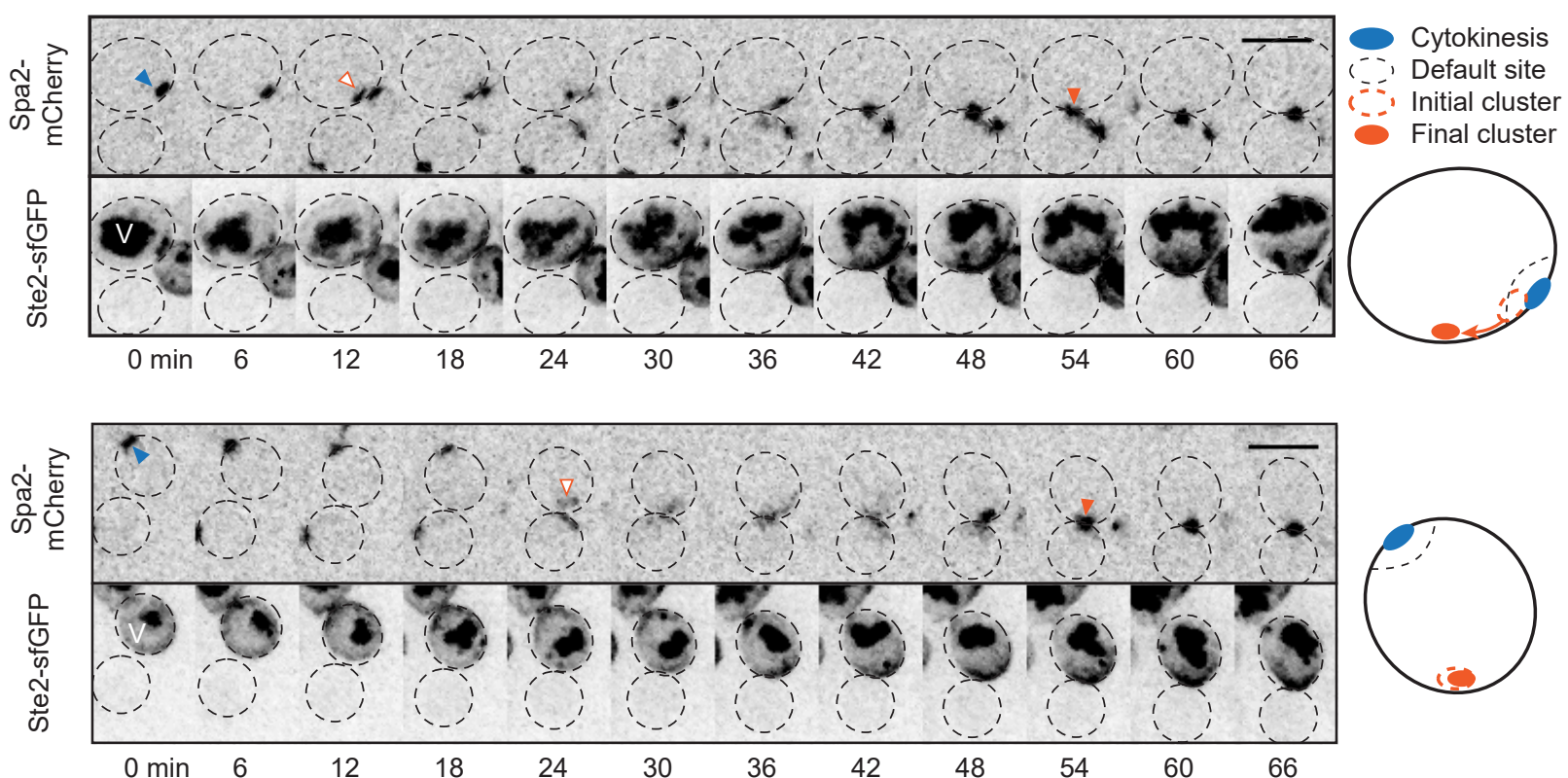

它 $\frac{0}{\mathbb{0}}$
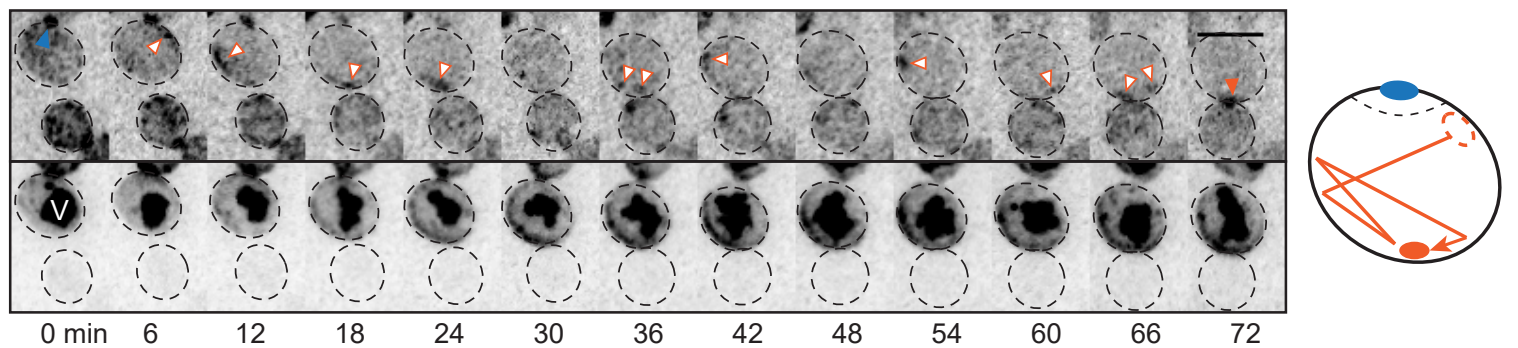
bioRxiv preprint doi: https://doi.org/10.1101/2020.09.07.285965; this version posted September 7, 2020. The copyright holder for this preprint Figure 2 cont.

Fig. 2. Behavior of mating cells before commitment to a partner. (A) The key signaling and polarity proteins in the pheromone pathway. When pheromone (red) binds receptor, polarity proteins assemble at the plasma membrane, and free G $\beta Y$ localizes the scaffold for MAPK signaling. (B) Cartoon depicting the quadrants (proximal, medial, distal) used to score the initial orientation of Ste20 relative to the mother-bud neck. If Ste20 polarizes randomly, then we expect $25 \%$ proximal, $25 \%$ distal, and $50 \%$ medial. (C) MATa STE20-GFP (DLY14364) and MATa STE20-tdTomato (DLY14413) cells were mixed and imaged during mating. Inverted maximum-projection montages illustrate representative mother-daughter pairs. Top, Ste20-tdTomato formed clusters at medial (M) and proximal (P) sites. Bottom, a Ste20-GFP cluster formed distal (D) to the neck (yellow oval). (D) Initial orientation of Ste20 clusters from the mating mix in $(C)$, and in subsets that were (adjacent) or were not (isolated) touching potential mating partners. *: goodness-of-fit test, $p=0.05$. (E) Cells harboring STE2-sfGFP and either BEM1-tdTomato (DLY22243) or SPA2-mCherry (DLY20712) were mixed with cells of the opposite mating type (BEM1-tdTomato, DLY22340 or SPA2-mCherry, DLY8503, respectively) and imaged during mating. Following Ste2 degradation, sfGFP accumulates in the vacuole (V). Ste2-sfGFP crescents gradually intensified in regions visited by polarity clusters. Blue arrowheads, accumulation of Spa2 or Bem1 at cytokinesis site; white arrowheads, polarity sites during indecisive phase; orange arrowheads, final polarity site. Cartoons summarize polarity behaviors. Scale bars: $5 \mu \mathrm{m}$. 


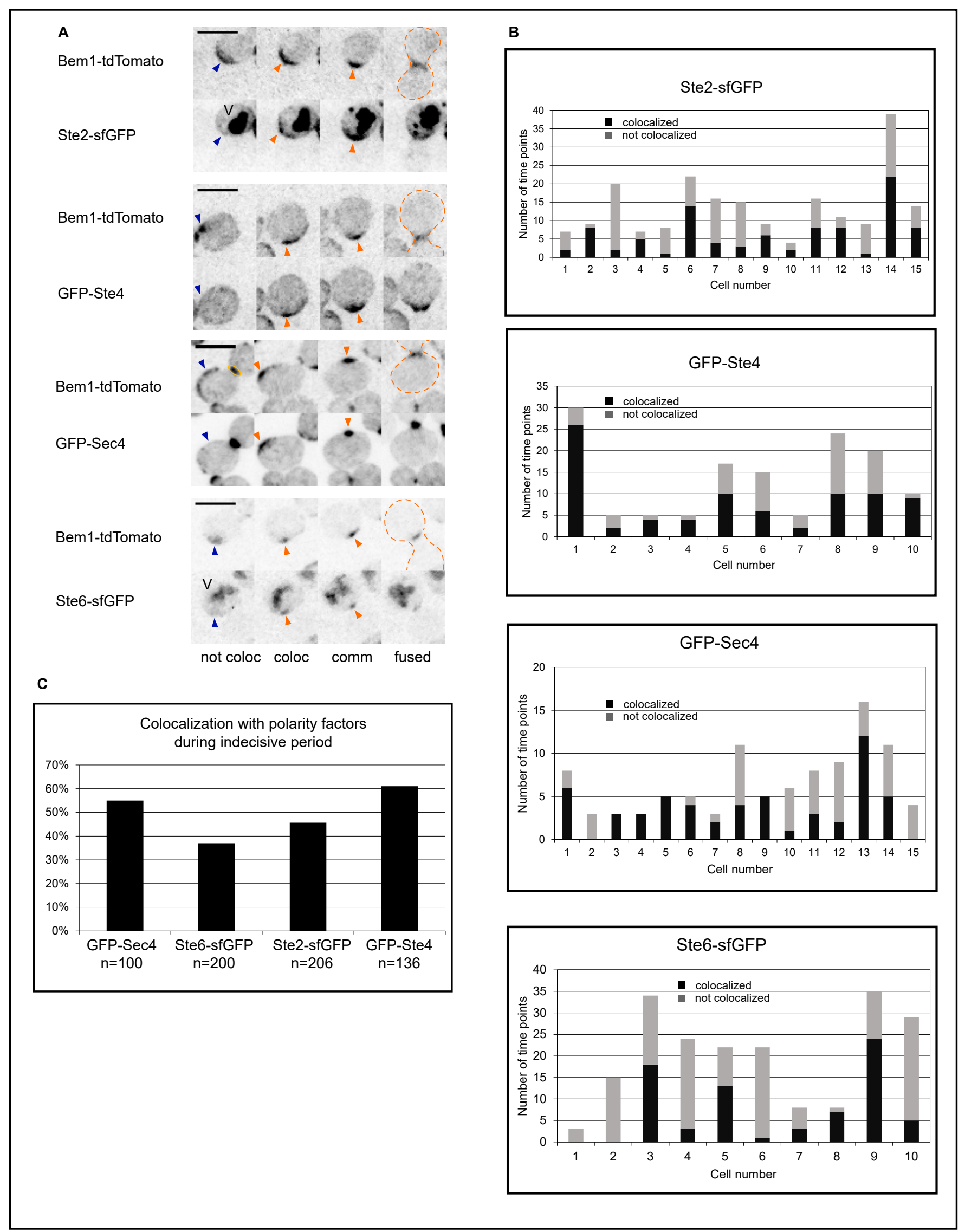


bioRxiv preprint doi: https://doi.org/10.1101/2020.09.07.285965; this version posted September 7, 2020. The copyright holder for this preprint Figure (which wasnpt certified by peer review) is the author/funder, who has granted bioRxiv a license to display the preprint in perpetuity. It is made

Fig. 3. Localization of pheromone secretion, sensing, and signaling proteins during the indecisive period. Strains harboring BEM1-tdTomato and either the $\alpha$-factor receptor STE2-sfGFP (DLY22243), G $\beta$ subunit GFP-STE4 (DLY23354), secretory vesicle marker GFP-SEC4 (DLY13771), or a-factor transporter STE6-sfGFP (DLY22355) were imaged during mating. (A) Representative images show examples of the indicated probes during the indecisive period (left two images), in committed cells (comm) and just after fusion (fused). Internal signal in Ste2-sfGFP and Ste6-sfGFP strains is due to sfGFP accumulation in the vacuole (V) following Ste2/Ste6 degradation. For time points when cells had clusters of Bem1-tdTomato, the green probe was scored as either not colocalized (not coloc, blue arrowheads) or colocalized (coloc, orange arrowheads). Yellow oval: cytokinesis site. Orange dashed line: zygote. Scale bars: $5 \mu \mathrm{m}$. (B) The colocalization frequency during the indecisive phase, scored as illustrated in (A), varied from cell to cell. Different cells had indecisive periods of different durations, and only some of the time points showed clear clusters of Bem 1 for scoring. Y-axis: number of time points scored per cell. (C) Overall colocalization frequency (\% of time points during the indecisive phase that show colocalization of the indicated probe with the Bem1 signal). $n$, total number of time points scored. 


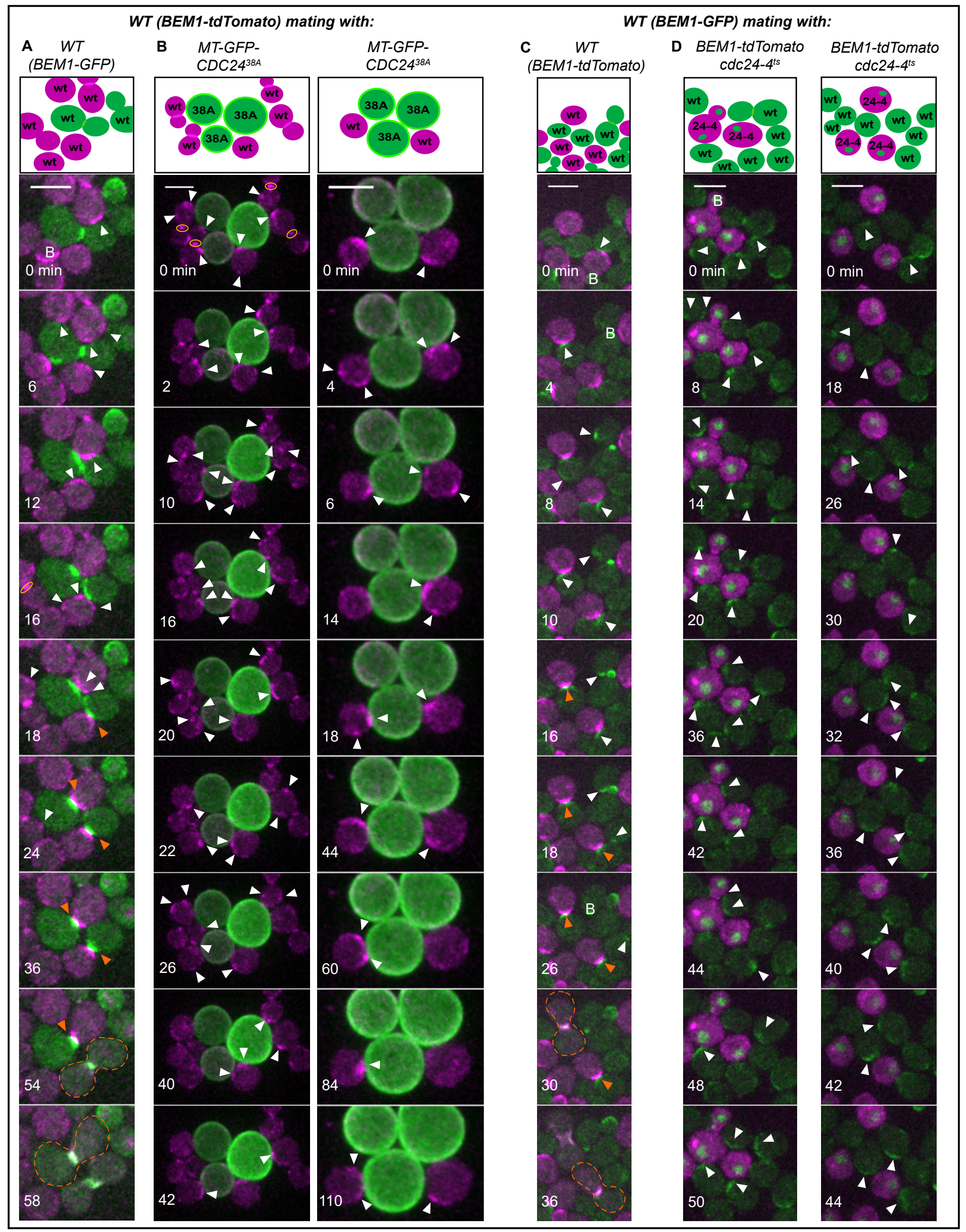


Figure (which wasnot certified by peer review) is the author/funder, who has granted bioRxiv a license to display the preprint in perpetuity. It is made
available under aCC-BY-NC-ND 4.0 International license. available under aCC-BY-NC-ND 4.0 International license.

Fig. 4. Wildtype cells do not commit to unpolarized partners. Selected time points from movies of mating mixes. Cartoons indicate cells in the selected montages at the start of the displayed imaging interval. B: bud. Yellow oval: mother-bud neck. White arrowhead: weak, mobile Bem1 cluster characteristic of indecisive cells, focusing on the magenta $(A, B)$ or green $(C, D)$ channel wildtype cells. Orange arrowheads: stably oriented Bem1 clusters characteristic of committed cells. Dashed outline: fused zygote. (A) MATa wildtype cells (BEM1-tdTomato, DLY12944) mixed with MATa wildtype cells (BEM1-GFP, DLY9069), imaged at $30^{\circ} \mathrm{C}$. (B) The same MATa wildtype strain mixed with MATa cells harboring membrane-targeted, constitutively-active Cdc24 (MT-GFP-CDC2438A, DLY23351) that do not make polarity clusters and imaged at $30^{\circ} \mathrm{C}$. Two montages are shown. (C) MATa wildtype cells (BEM1-GFP, DLY9070) mixed with MATa wildtype cells (BEM1-tdTomato, DLY12943), imaged at $37^{\circ} \mathrm{C}$. (D) The same MATa wildtype strain mixed with MATa cells harboring cdc24-4ts (DLY23256, green nuclei indicate G1 cells), imaged at $35^{\circ} \mathrm{C}$. Two montages are shown. Scale bars: $5 \mu \mathrm{m}$. 
bioRxiv preprint doi: https://doi.org/10.1101/2020.09.07.285965; this version posted September 7, 2020. The copyright holder for this preprint

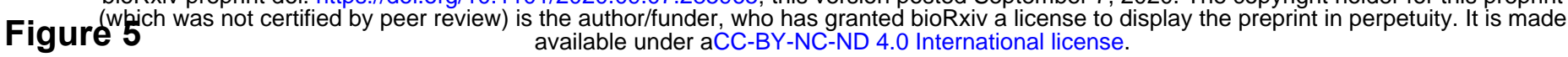

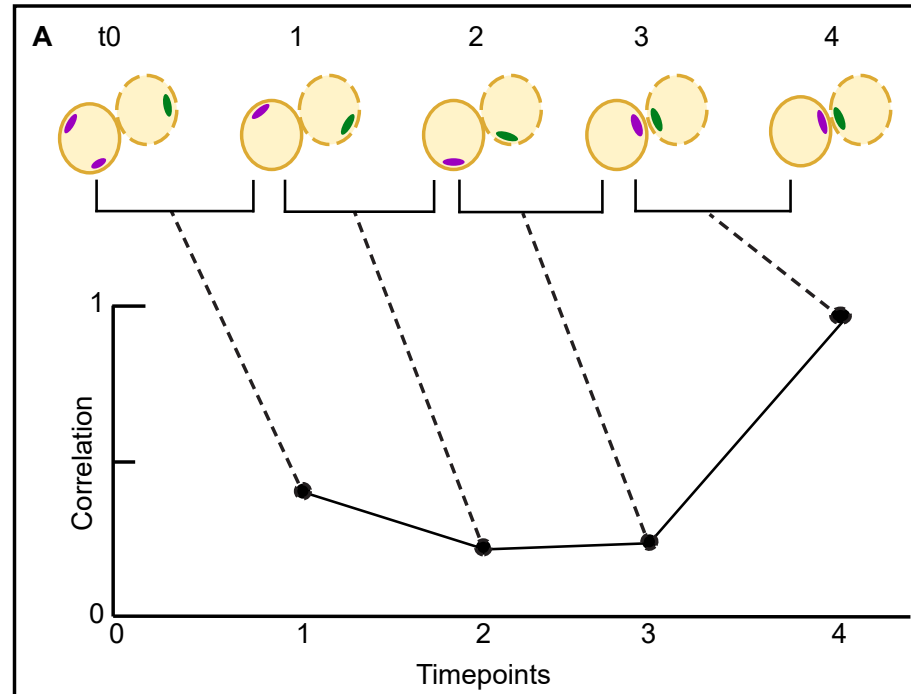

B
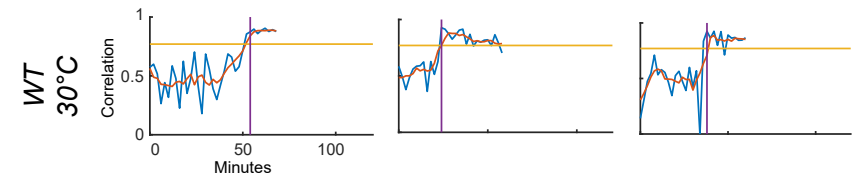

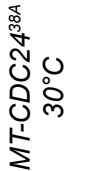
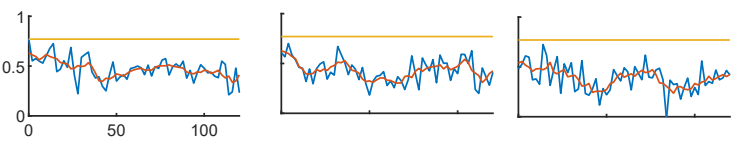

$5 \stackrel{0}{\mathrm{i}}$
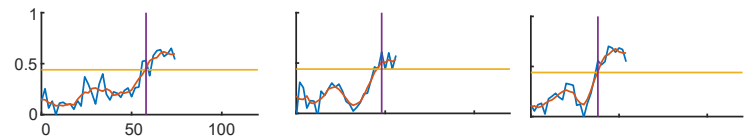

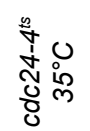
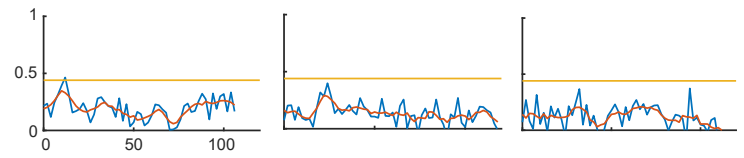

Raw correlation

Smoothed correlation
Correlation $=0.77\left(30^{\circ} \mathrm{C}\right)$ or $0.44\left(35^{\circ} \mathrm{C}\right)$

C
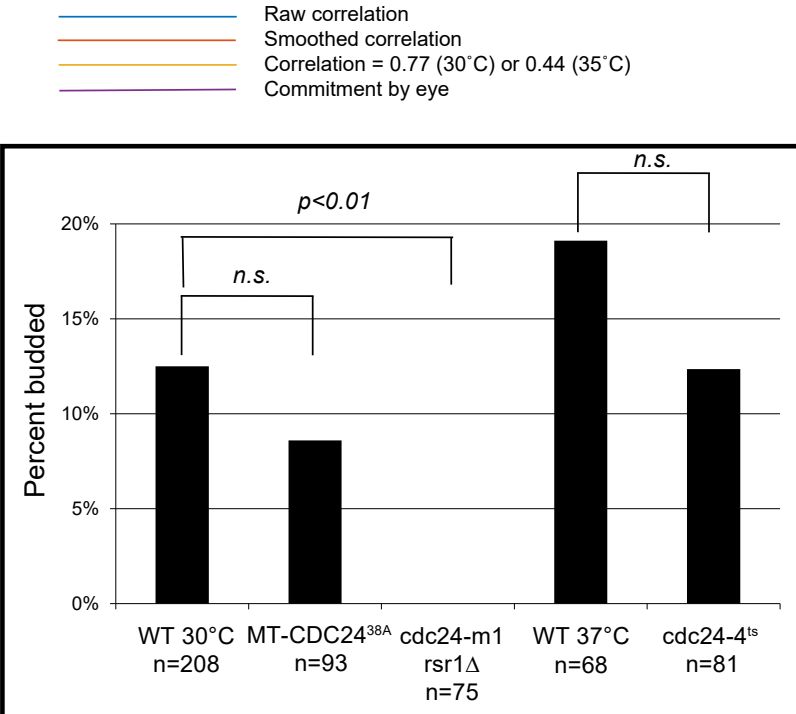

Fig. 5. Scoring commitment and cell cycle arrest in mating mixes. (A) Cartoon illustrating spatial autocorrelation algorithm to score commitment. The spatial distribution of Bem1 pixel intensities in a cell of interest (magenta clusters) are compared at consecutive time points to yield a normalized correlation measure between 0 (no correlation) and 1 (perfect correlation). Strong and stably oriented polarity sites characteristic of committed cells $(3,4)$ yield a high correlation while weaker, mobile polarity sites characteristic of indecisive cells $(0,1,2)$ yield a low correlation. (B) Example spatial autocorrelation traces from wildtype cells mixed with either wildtype partners or the indicated non-clustering mutants as in Fig. 4. Horizontal yellow line: threshold autocorrelation used to call commitment. Purple vertical line: commitment time as scored visually. Wildtype cells attempting to mate with unpolarized mutants did not reach the threshold, even after $100 \mathrm{~min}$. (C) Wildtype cells adjacent to $\mathrm{G} 1$-phase cells of opposite mating type sometimes return to the cell cycle and form a bud. The percent of wildtype cells that budded was determined from the mating mixes with the indicated partners (genotypes as in Fig. 4 and 6). 


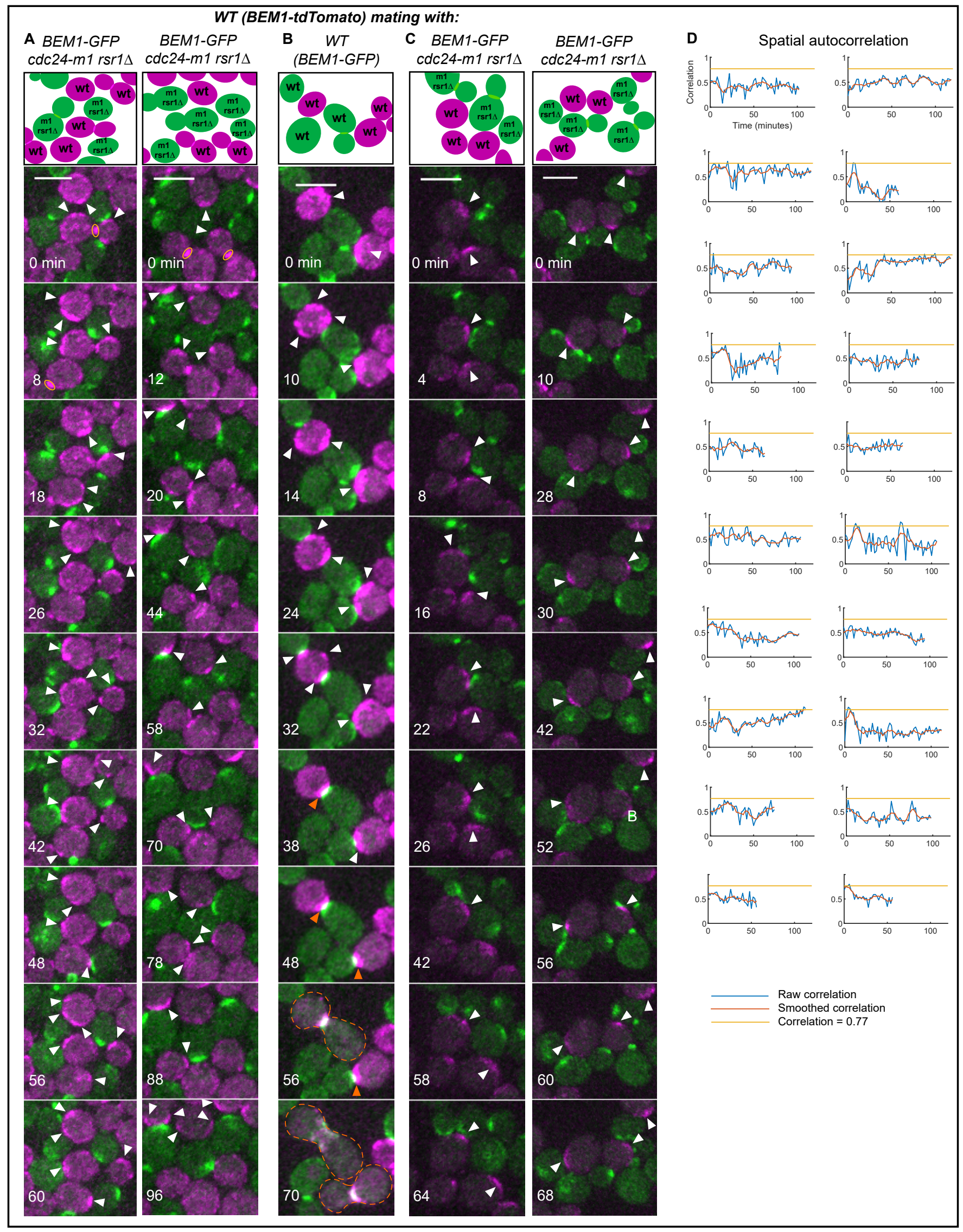


bioRxiv preprint doi: https://doi.org/10.1101/2020.09.07.285965; this version posted September 7, 2020. The copyright holder for this preprint

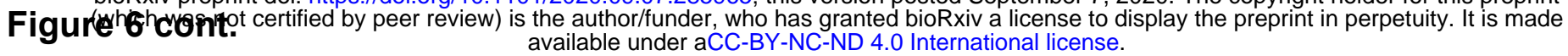

Fig. 6. Wildtype cells do not commit to mutants with constitutively mobile polarity sites. (A-C) Selected time points from movies of mating mixes. Yellow oval: mother-bud neck. White arrowhead: weak mobile Bem1 cluster characteristic of indecisive cells, focusing on the magenta $(A)$ or green $(B, C)$ channel wildtype cells. Orange arrowheads: stably oriented Bem1 clusters characteristic of committed cells. Dashed outline: fused zygote. (A) MATa wildtype cells (BEM1-tdTomato, DLY12944) were mixed with MATa mutants that form constitutively mobile polarity clusters (cdc24- $m 1$ rsr1 $\triangle B E M 1-G F P$, DLY22797) and imaged at $30^{\circ} \mathrm{C}$. (B) MATa wildtype cells (BEM1-GFP, DLY9070) were mixed with MATa wildtype cells (BEM1-tdTomato, DLY12943). Control mating mix in which mating type and fluorophore are switched relative to Fig. 4A. (C) MATa wildtype cells (BEM1-tdTomato, DLY12943) were mixed with MATa mutants that form constitutively mobile polarity clusters (cdc24-m1 rsr1 $B E M 1-G F P$, DLY23612). (D) Spatial autocorrelation traces of representative wildtype cells mixed with $c d c 24-m 1$ rsr1 $\Delta$ cells from (A). 
bioRxiv preprint doi: https://doi.org/10.1101/2020.09.07.285965; this version posted September 7, 2020. The copyright holder for this preprint fwhich was not certified by peer review) is the author/funder, who has granted bioRxiv a license to display the preprint in perpetuity. It is made

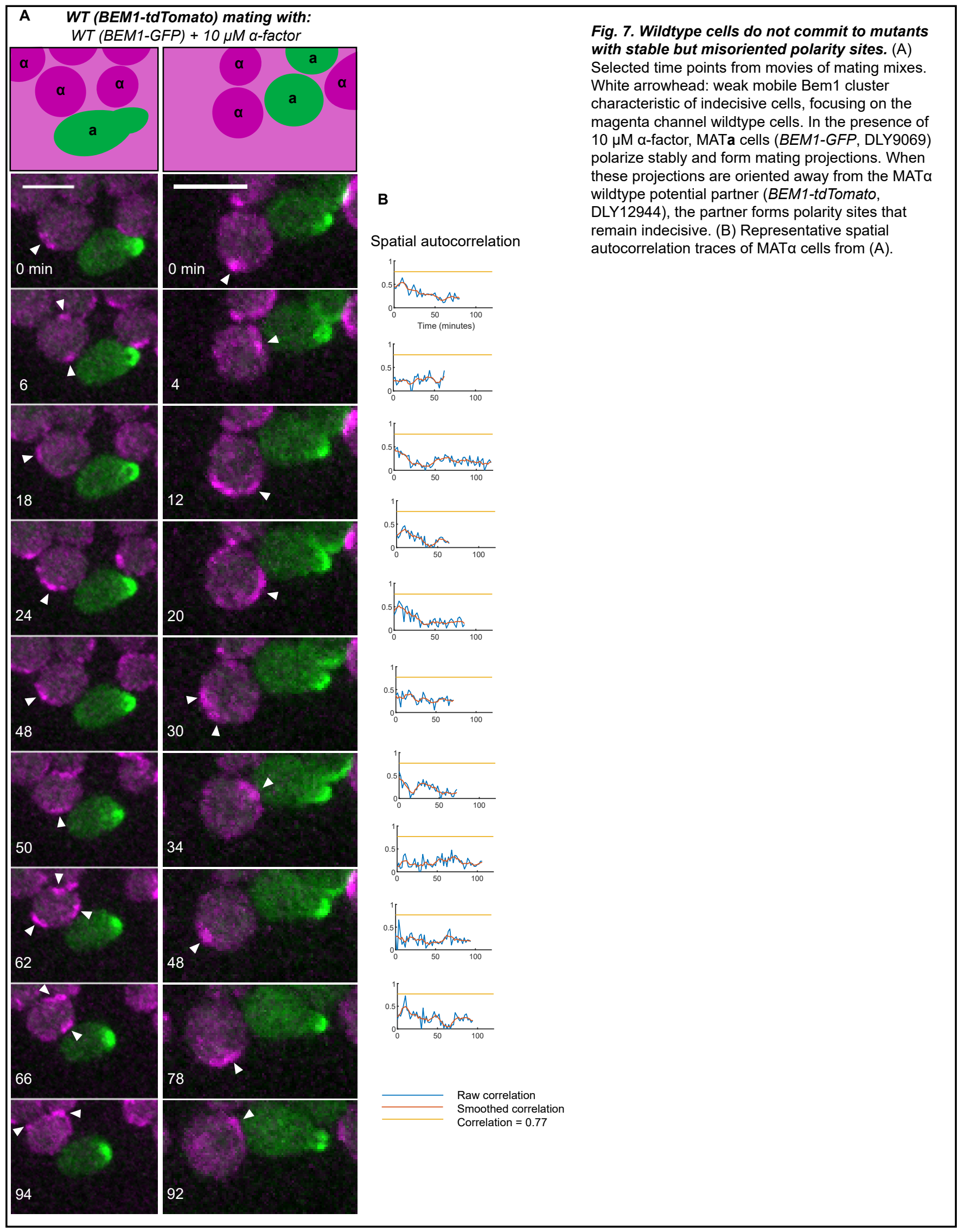


bioRxiv preprint doi: https://doi.org/10.1101/2020.09.07.285965; this version posted September 7, 2020. The copyright holder for this preprint Figure (wjich was not certified by peer review) is the author/funder, who has granted bioRxiv a license to display the preprint in perpetuity. It is made
available under aCC-BY-NC-ND 4.0 International license.

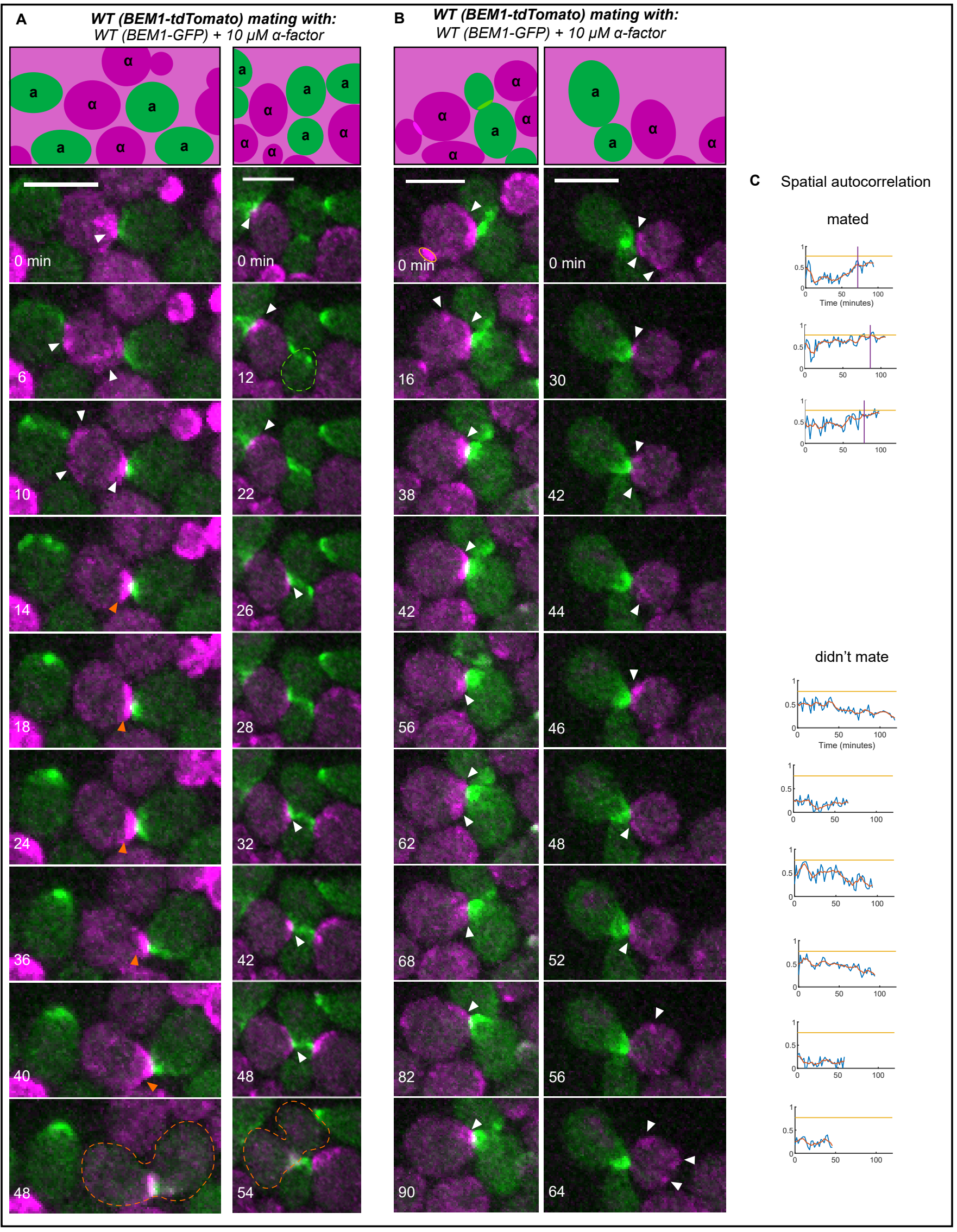


Fig. 8. Default mating requires fortuitous correct orientation by the "confused" partner. (A,B) Selected time points from movies of the same mating mixes as in Fig. 7. (A) Examples of successful mating. (B) Examples in which mating fails despite apparently correct orientation by the confused partner. (C) Representative spatial autocorrelation traces of MATa cells that did (top three) or did not (bottom six) mate. 
bioRxiv preprint doi: https://doi.org/10.1101/2020.09.07.285965; this version posted September 7, 2020. The copyright holder for this preprint Figurengich was not certified by peer review) is the author/funder, who has granted bioRxiv a license to display the preprint in perpetuity. It is made available under aCC-BY-NC-ND 4.0 International license.

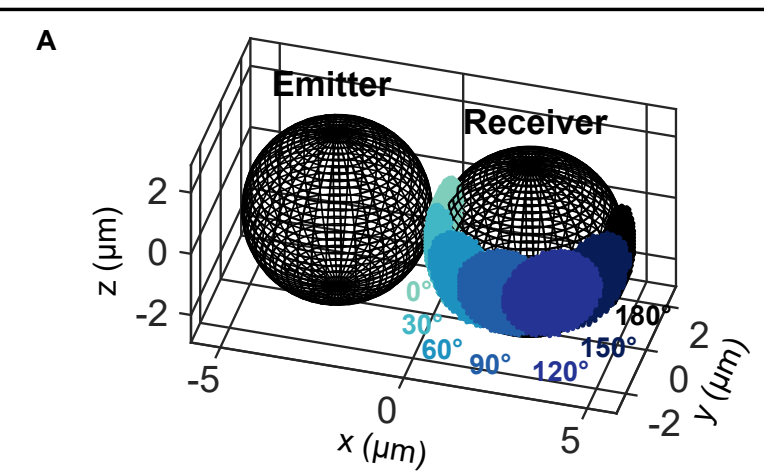

B Local secretion

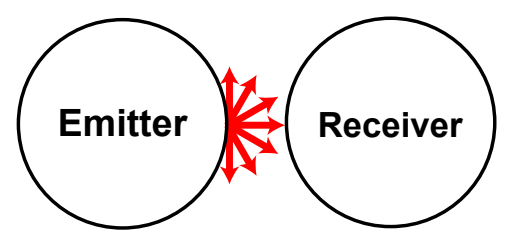

Global secretion

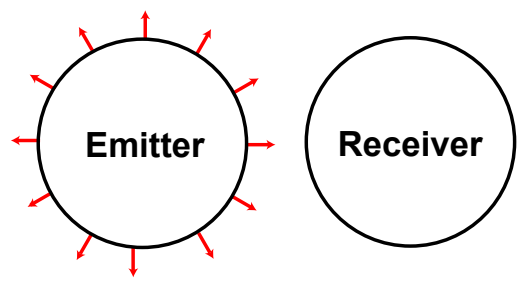

Average pheromone concentration at receiver surface

D

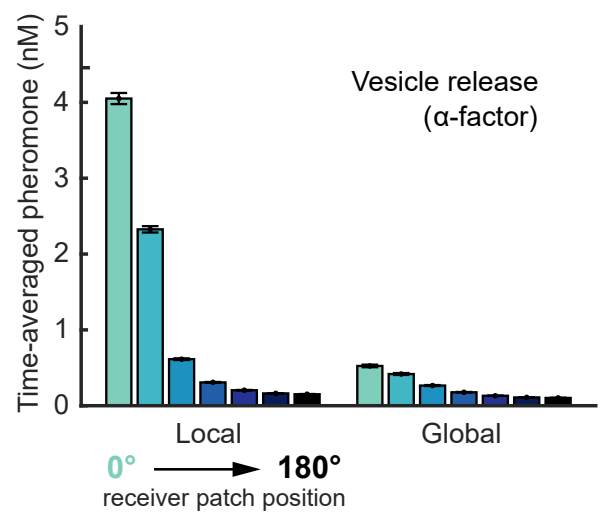

$\mathbf{F}$

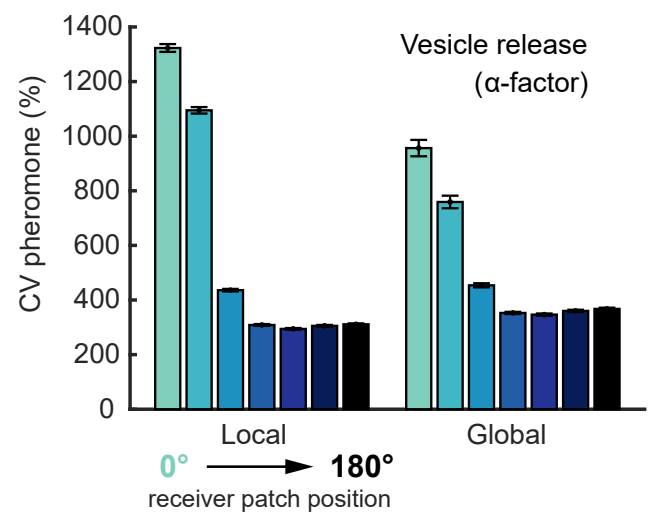

C

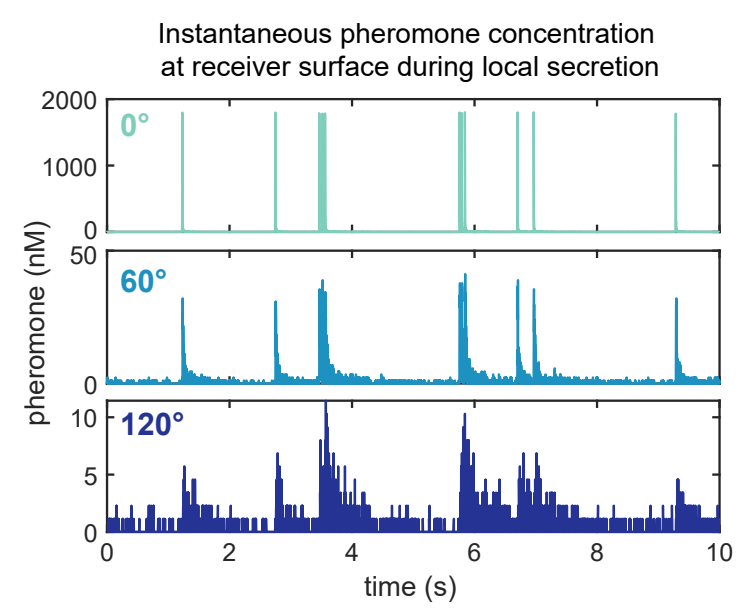

E

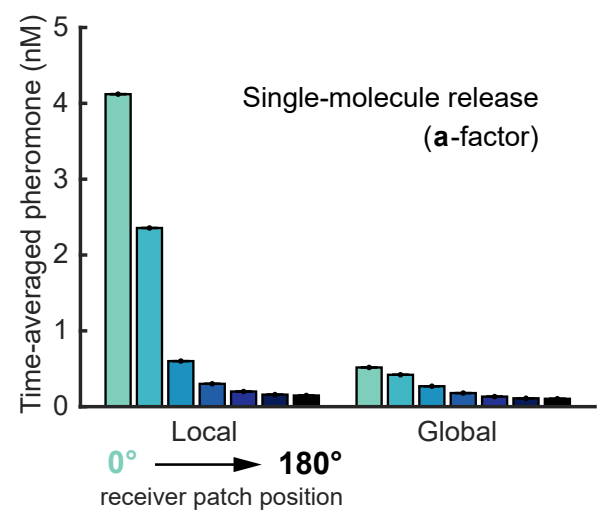

G

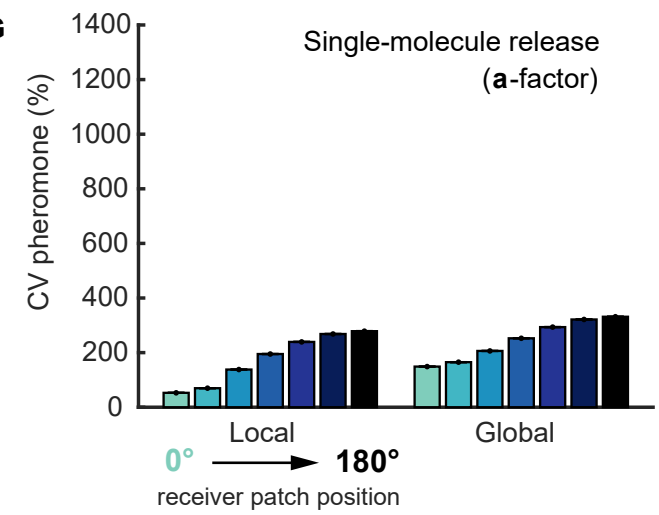


Fig. 9 . Simulations of the pheromone receiver's landscape for two touching cells. (A) Model setup for emitter and receiver cells shown at scale. Seven patch positions on the receiver $\left(0^{\circ}\right.$ to $180^{\circ}$, changing colors) were used to measure local pheromone concentrations. (B) Local versus global secretion. In local secretion, pheromone was released just at the emitter pole abutting the receiver. In global secretion, pheromone was released uniformly just at the emitter surface. $(C)$ Instantaneous pheromone concentration at different positions (color) near receiver's surface over time during local vesicle secretion. (D,E) Time-averaged pheromone concentration at different positions (color) on receiver's surface for both vesicle and single-molecule release. $(F, G)$ Coefficient of variation $(C V)$ for $(D, E)$. All bars show mean \pm s.e.m., $n=300$ realizations. 
bigRxiv preprint doi: https://doi.org/10.1101/2020.09.07.285965; this version posted September 7, 2020. The copyright holder for this preprint

Figurewidh was not certified by peer review) is the author/funder, who has granted bioRxiv a license to display the preprint in perpetuity. It is made available under aCC-BY-NC-ND 4.0 International license.

BEM1-tdTomato mating with:

BEM1-tdTomato MT-GFP-CDC24 ${ }^{38 A}$

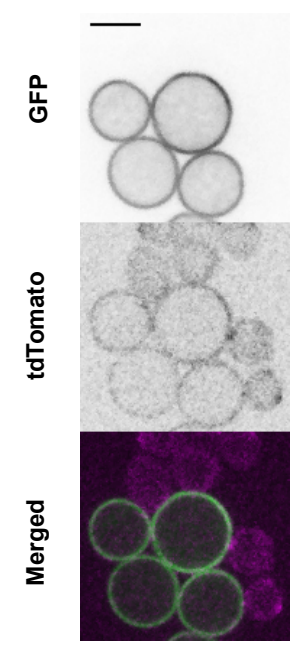

Fig. S1. Overexpression of membrane-targeted Cdc24 blocks polarization. Medial

plane confocal images of cells induced to express membrane-targeted, phospho-site mutant GFP-CDC24 ${ }^{38 A}$ (MT-GFP-CDC24 $4^{38 A}$ BEM1-tdTomato, DLY23351) and mixed with wildtype cells (BEM1-tdTomato, DLY12944). Scale bar: $5 \mu \mathrm{m}$. 

BEM1-GFP (a) x BEM1-tdTomato $(\alpha), 30^{\circ} \mathrm{C}$

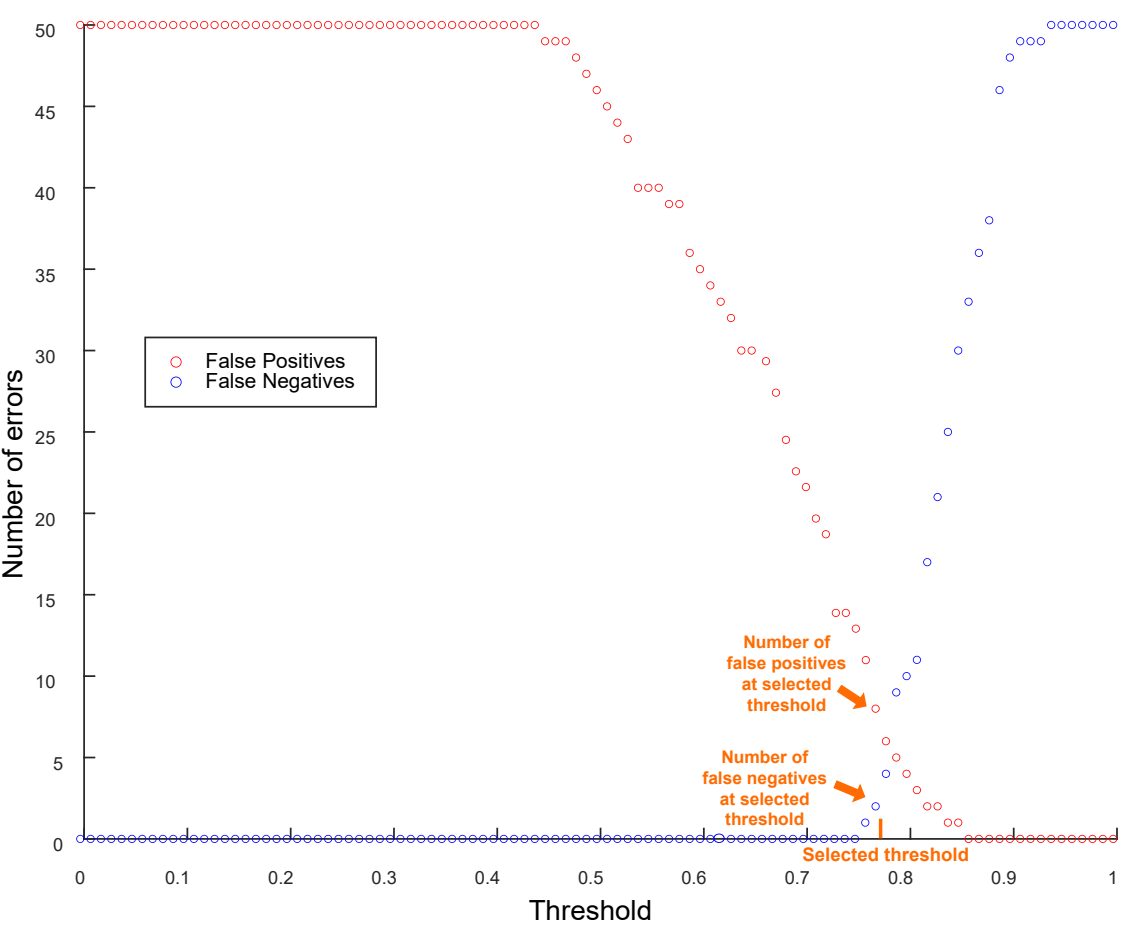

Threshold determination for spatial autocorrelation analysis BEM1-tdTomato (a) x BEM1-GFP (a), $35^{\circ} \mathrm{C}$

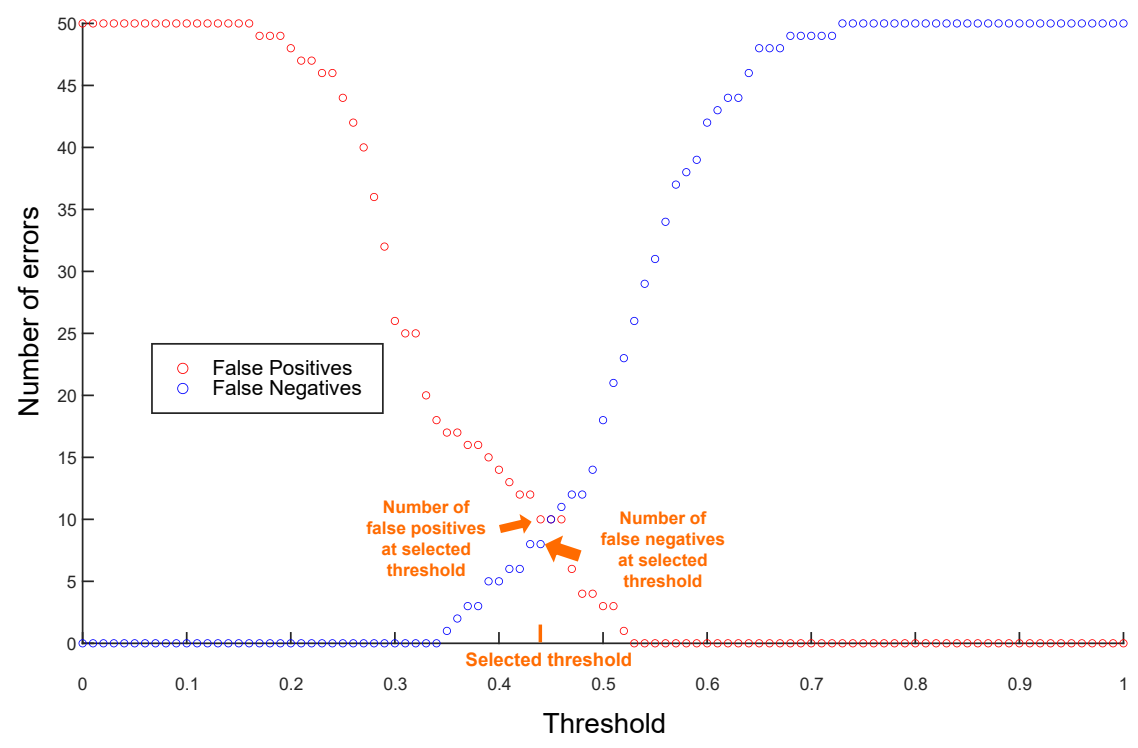


bioRxiv preprint doi: https://doi.org/10.1101/2020.09.07.285965; this version posted September 7, 2020. The copyright holder for this preprint (which was not certified by peer review) is the author/funder, who has granted bioRxiv a license to display the preprint in perpetuity. It is made Figure S2 cont. available under aCC-BY-NC-ND 4.0 International license.

Fig. S2. Threshold determination for spatial autocorrelation analyses. (A) The number of false negatives (in which the spatial autocorrelation trace did not cross the threshold but did commit as scored visually) and false positives (in which the spatial autocorrelation trace crossed the threshold $>4$ min before commitment as scored visually) as a function of commitment threshold for wildtype $x$ wildtype pairs at $30^{\circ} \mathrm{C}$. A threshold of 0.77 was selected (orange tick). (B) Similar analysis for wildtype $\mathrm{x}$ wildtype pairs at $35^{\circ} \mathrm{C}$. A threshold of 0.44 was selected (orange tick). 


\section{Figure S3}

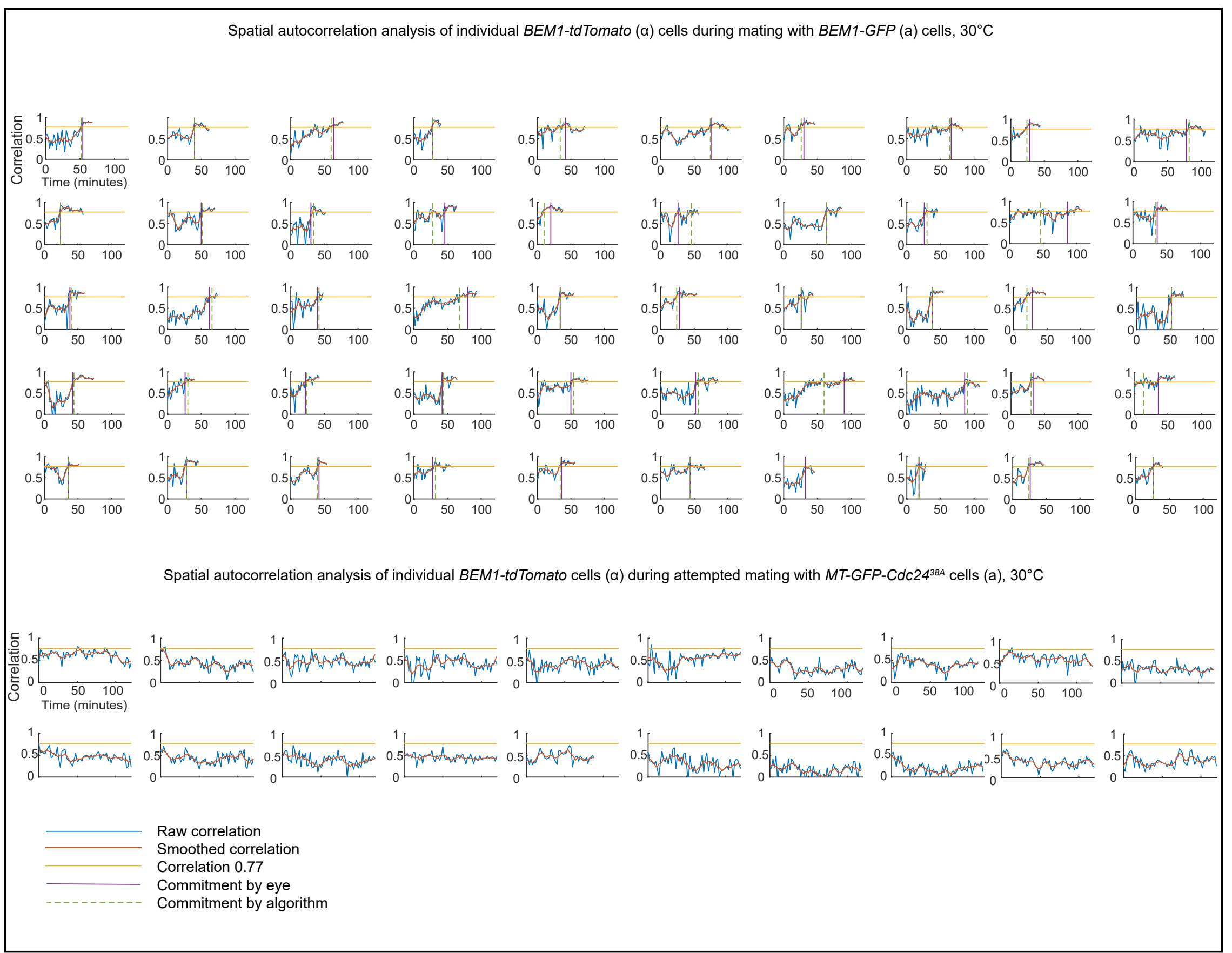




\section{Figure S3 cont.}

Fig. S3. Spatial autocorrelation traces for cells at $30^{\circ} \mathrm{C}$. (A) Wildtype by wildtype mixes as in Fig. $4 \mathrm{~A}$. Traces begin at the time of the cell's entry into G1 and end at the time point preceding fusion. X-axis: Time (min). Y-axis: spatial autocorrelation (yellow line: commitment threshold). Commitment to a partner as determined visually (vertical purple line) or by crossing the threshold (dashed green line). (B) Similar analysis for wildtype cells mating with MT-Cdc24 ${ }^{38 A}$ partners as in Fig. 4B. 


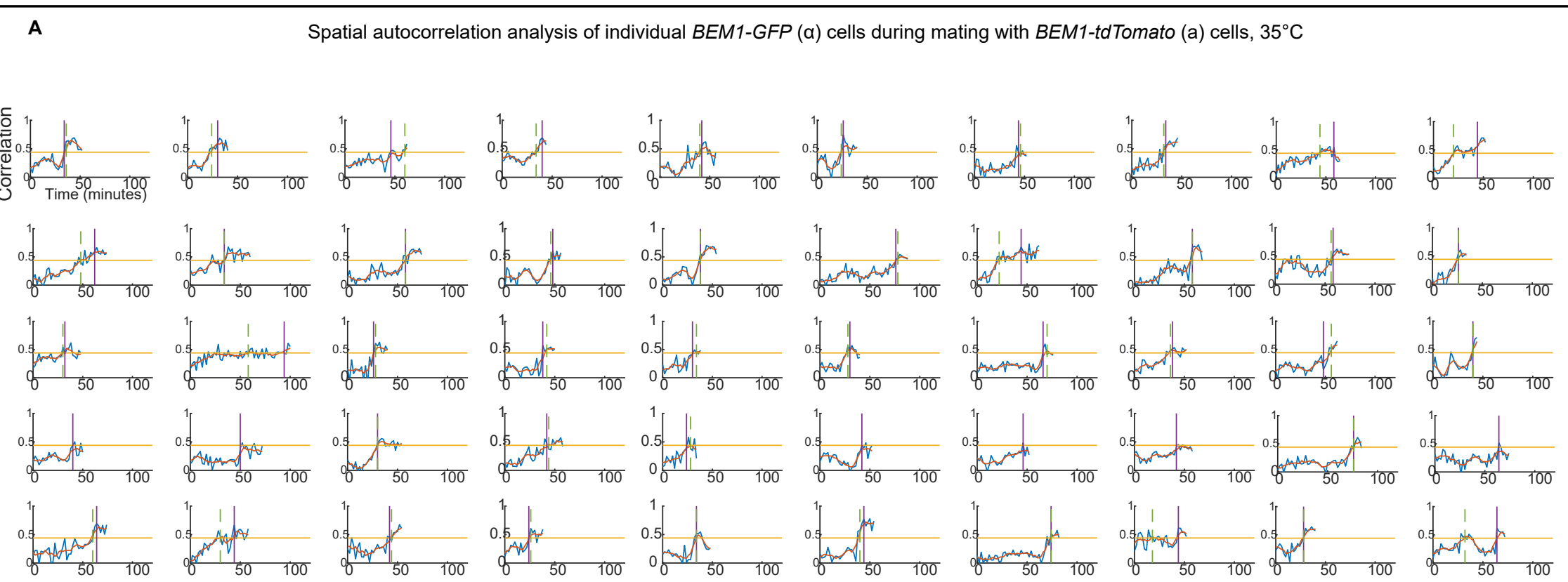

B

Spatial autocorrelation analysis of individual BEM1-GFP (a) cells during mating with cdc24-4 (a) cells, $35^{\circ} \mathrm{C}$
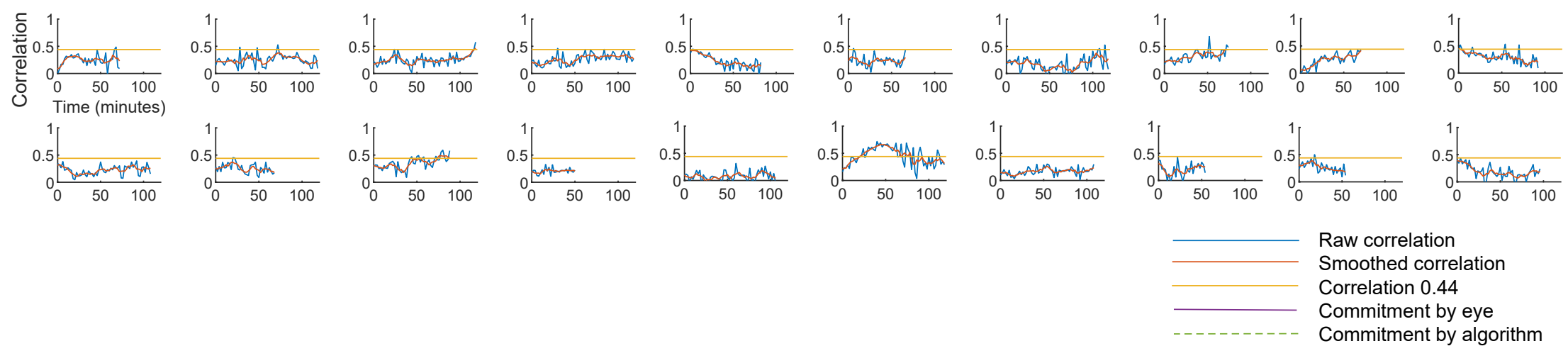

Fig. S4. Spatial autocorrelation traces for cells at $35^{\circ} \mathrm{C}$. (A) Wildtype by wildtype mixes. Traces begin at the time of the cell's entry into $\mathrm{G} 1$ and end at the time point preceding fusion. $X$ axis: Time (min). Y axis: spatial autocorrelation (yellow line: commitment threshold). Commitment to a partner as determined visually (vertical purple line) or by crossing the threshold (dashed green line). (B) Similar analysis for wildtype cells mating with cdc24-4ts partners as in Fig. 4D. 
bioRxiv preprint doi: https//doi.org/10.1101/2020.09.07 285965. this version posted September 7, 2020. The copyright holder for this preprint Figurevis was not certified by peer review) is the author/funder, who has granted bioRxiv a license to display the preprint in perpetuity. It is made available under aCC-BY-NC-ND 4.0 International license.

A

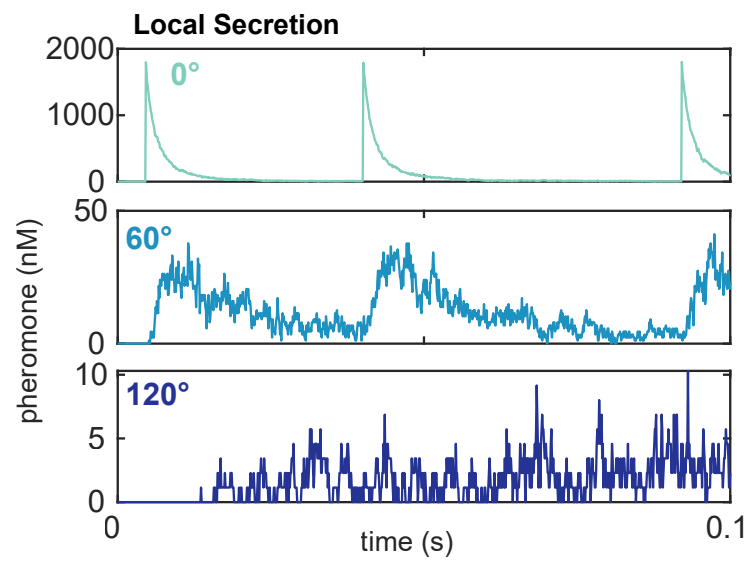

B
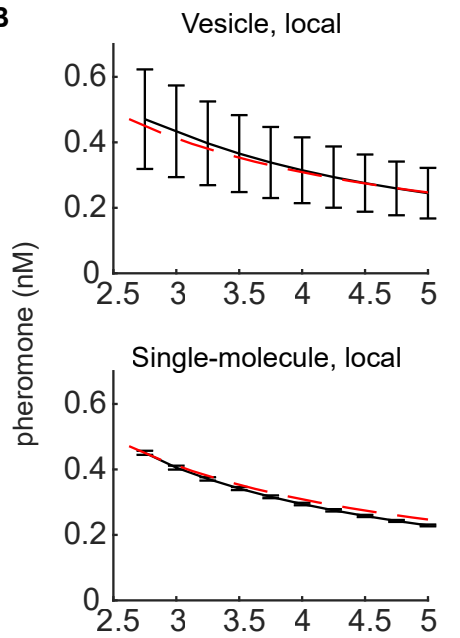

Distance from emitter center, $\mu \mathrm{m}$
Vesicle, global
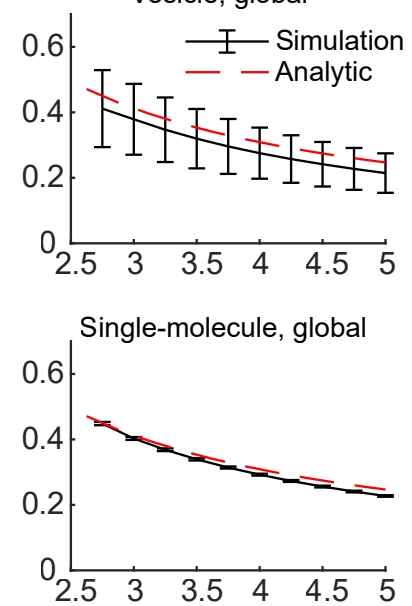

Global secretion

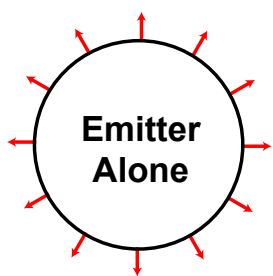

Figure S5. Validation of the pheromone simulations and additional detail. (A) Pheromone concentrations perceived at three different patches in a single simulation as in Fig. 9C, but zoomed in to show 0.1 second along the $x$-axis. (B) Simulations of the emitter alone, comparing concentrations in a spherical $250 \mathrm{~nm}$ shell (not a patch) at the indicated distance from the center of the emitter versus the steady-state analytic solution of the diffusion equation under equivalent conditions. Bars show mean \pm s.d., $n=30$. 